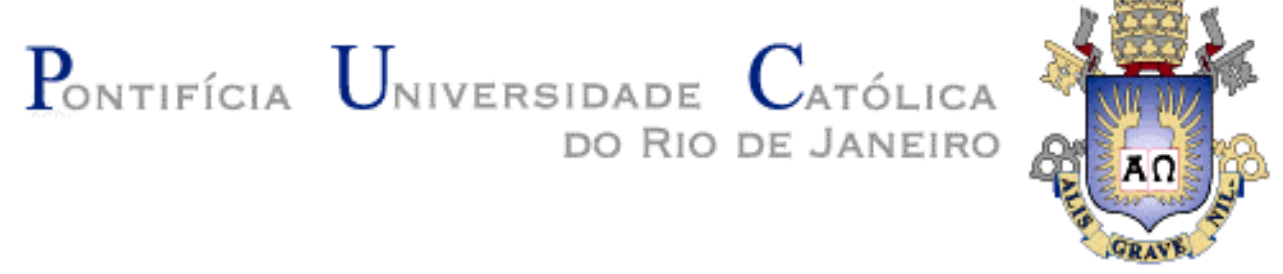

Débora Pontes Oliveira Silva

\title{
Experienciação das rotinas organizacionais durante 0 período de isolamento social imposto pela pandemia da Covid-19
}

\section{Dissertação de Mestrado}

Dissertação apresentada como requisito parcial para obtenção do grau de Mestre pelo Programa de Pósgraduação em Administração de Empresas do Departamento de Administração da PUC-Rio.

Orientadora: Prof ${ }^{a}$. Sandra Regina Rocha Pinto 
Débora Pontes Oliveira Silva

\section{Experienciação das rotinas organizacionais durante 0 período de isolamento social imposto pela pandemia da Covid-19}

Dissertação apresentada como requisito parcial para obtenção do grau de Mestre pelo Programa de Pós-Graduação em Administração de Empresas da PUC-Rio. Aprovada pela Comissão Examinadora abaixo.

Profa. Sandra Regina Rocha Pinto

Orientadora

Departamento de Administração - PUC-Rio

Profa. Maria Isabel Peixoto Guimarães Departamento de Administração - PUC-Rio

Prof. Mario Couto Soares Pinto Escola de Negócios e Seguros 
Todos os direitos reservados. É proibida a reprodução total ou parcial do trabalho sem a autorização da universidade, da autora e do orientador.

\title{
Débora Pontes Oliveira Silva
}

Graduou-se em Direito pela Universidade Cândido Mendes em 2010. Concluiu LLM em Direito Corporativo em 2013 pelo IBMEC-RJ. Concluiu MBA em Gestão de Projetos em 2019 pela Universidade do Estado do Rio de Janeiro e possui 11 anos de experiência em gerenciamento de riscos jurídicos.

Ficha Catalográfica

\begin{abstract}
Silva, Débora Pontes Oliveira
Experienciação das rotinas organizacionais durante o período de isolamento social imposto pela pandemia da Covid-19 / Débora Pontes Oliveira Silva; orientadora: Sandra Regina da Rocha Pinto. - Rio de Janeiro PUC, Departamento de Administração, 2021.
\end{abstract}

72 f.: il. ; $30 \mathrm{~cm}$

1. Dissertação (mestrado) - Pontifícia Universidade Católica do Rio de Janeiro, Departamento de Administração.

Inclui referências bibliográficas.

1. Administração - Teses. 2. Rotinas organizacionais. 3. Artefatos. 4. Isolamento social. I. Rocha-Pinto, Sandra Regina da. II. Pontifícia Universidade Católica do Rio de Janeiro. Departamento de Administração. III. Título. 
Ao meu pai e a minha mãe pelo apoio e amor incondicionais.

À minha avó, Terezinha, que me guia de onde estiver. (in memoriam) 


\section{Agradecimentos}

A Deus, por sempre colocar o chão sob meus pés.

À professora Sandra, minha orientadora, pela generosidade no compartilhamento de seus saberes e pela compreensão, amorosidade e parceria durante o processo de elaboração dessa dissertação.

Às professoras Alessandra Costa e Eliane Leite que estimularam, a cada aula, o aprofundamento do pensamento crítico e a paixão pelo principal ativo da empresa: o ser humano.

Aos professores Maria Isabel Peixoto Guimarães e Mario Couto Soares Pinto que gentilmente aceitaram compor a comissão examinadora deste trabalho e agregaram à pesquisa com valorosas contribuições.

Aos meus pais que além de terem me dado a vida, sempre me deram bons exemplos de como vivê-la respeitando a mim e ao próximo.

A minha avó, Teresinha, in memoriam, que me mostrou desde cedo que é preciso força e doçura para enfrentar os percalços da vida.

A minha avó, Lourdes, in memoriam, que se despediu de nós este ano, antes de ter a oportunidade de ver sua neta mestre.

A minha madrinha, Regina, que acompanha desde a mais tenra idade cada passo da minha trajetória.

Às amigas Elaine e Gilda, sempre presentes, em todos os momentos. Com vocês a caminhada fica mais fácil.

Ao querido Eduardo, que me apresentou a PUC-RIO e o IAG e fez nascer em mim o carinho que ele já carregava por esta instituição. Sem o incentivo e apoio dele, eu não teria me inscrito no curso e não teria tido a oportunidade de viver mais essa transformação de mim. 
Aos profissionais que participaram da pesquisa e que cederam a mim parte de seu bem mais precioso: o tempo.

Aos funcionários do IAG, em especial a Gisele e a Tereza, sempre disponíveis, alegres e com espírito de cooperação.

À Pontifícia Universidade Católica do Rio de Janeiro - PUC-RJ e a todos os seus funcionários e colaboradores. Durante o curso de mestrado compreendi a grandiosidade e a responsabilidade de ser filha da PUC.

O presente trabalho foi realizado com apoio da Coordenação de Aperfeiçoamento de Pessoal de Nível Superior - Brasil (CAPES) - Código de Financiamento 001. 


\section{Resumo}

Silva, Débora Pontes Oliveira; Rocha Pinto, Sandra Regina. Experienciação das rotinas organizacionais durante o período de isolamento social imposto pela pandemia da Covid-19. Rio de Janeiro, 2021. 72 p. Dissertação de Mestrado - Departamento de Administração, Pontifícia Universidade Católica do Rio de Janeiro.

A partir de dezembro de 2019, o mundo tomou conhecimento da existência da Covid-19 (FIOCRUZ, 2020). As peculiaridades da doença, exigiram a adoção de medidas de distanciamento social (OMS, 2020). Na cidade do Rio de Janeiro, a partir de 16 de março de 2020, foi determinado o fechamento de todas as empresas que não prestassem serviços essenciais (ESTADO DO RIO DE JANEIRO, 2020). Nesse contexto, as empresas se viram compelidas a adaptar as rotinas organizacionais para manter suas operações. Emergiu, então, a relevância de investigar como profissionais experienciaram suas rotinas organizacionais durante o período de isolamento social imposto pela pandemia da Covid-19. A partir de uma abordagem Fenomenográfica, foram entrevistados 30 profissionais. Das análises, retornaram três categorias descritivas: i) a preservação das rotinas organizacionais; ii) a (re)organização da dimensão tempo-espaço e iii) a capacidade de inovação. Para relacioná-las, foram identificadas quatro dimensões explicativas: i) o dinamismo nos componentes operativos das rotinas; ii) os aspectos técnicoscomportamentais dos atores envolvidos; iii) os aspectos gerenciais sobre as rotinas e iv percepção de segurança. Os achados sugerem que as concepções dos profissionais evoluíram da operação mecânica da rotina para uma percepção de engajamento coletivo para manutenção da própria empresa; do objetivo de manter os padrões preestabelecidos, para uma percepção de oportunidade para inovação e diferenciação. Além disso, o estudo reforça a indissociável relação entre os aspectos ostensivo e performativos das rotinas e os artefatos.

\section{Palavras-chave}

Rotinas organizacionais; artefatos; isolamento social 


\section{Abstract}

Silva, Débora Pontes Oliveira; Rocha Pinto, Sandra Regina (Advisor). Experiencing organizational routines during the period of social isolation imposed by the Covid-19 pandemic. Rio de Janeiro, 2021. 72 p. Dissertação de Mestrado - Departamento de Administração, Pontifícia Universidade Católica do Rio de Janeiro.

As of December 2019, the world became aware of the existence of Covid-19 (FIOCRUZ, 2020). The peculiarities of the disease required the adoption of measures of social distancing (WHO, 2020). In the city of Rio de Janeiro, as of March 16, 2020, all companies that did not provide essential services were closed (ESTADO DO RIO DE JANEIRO, 2020). In this context, companies found themselves compelled to adapt organizational routines to maintain their operations. The relevance of investigating how professionals experienced their organizational routines during the period of social isolation imposed by the Covid-19 pandemic emerged. From a Phenomenographic approach, 30 professionals were interviewed. From the analyses, three descriptive categories returned: i) the preservation of organizational routines; ii) the (re)organization of the time-space dimension and iii) the capacity for innovation. To relate them, four explanatory dimensions were identified: i) the dynamism in the operative components of the routines; ii) the technical-behavioral aspects of the actors involved; iii) managerial aspects of routines and iv perception of safety. The findings suggest that the professionals' conceptions evolved from the mechanical operation of the routine to a perception of collective engagement to maintain the company itself; from the objective of maintaining pre-established standards, to a perception of opportunity for innovation and differentiation. Furthermore, the study reinforces the inseparable relationship between the ostensive and performative aspects of routines and artifacts.

\section{KeyWords}

Organizational routines; artifacts; social isolation 


\section{Sumário}

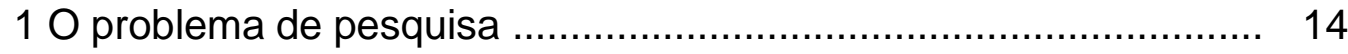

1.1 Introdução ................................................................. 14

1.2 Relevância do estudo ........................................................ 15

1.3 Objetivos e delimitação do estudo ..................................... 16

2 Referencial teórico …......................................................... 18

2.1 Rotinas Organizacionais ................................................... 18

2.1.1 Aspectos ostensivo e performativo ................................... 19

2.1.2 Artefatos ................................................................... 20

2.1.3 Rotinas organizacionais e a dimensão tempo-espaço ............. 24

2.1.4 Rotinas organizacionais e inovação ................................. 25

3 Procedimentos metodológicos ............................................... 28

3.1 Aspectos epistemológicos e ontológicos ............................... 28

3.2 Método fenomenográfico ............................................... 28

3.3 Justificativa para adoção da abordagem fenomenográfica ......... 29

3.4 Seleção dos sujeitos e coleta de dados ................................ 30

3.5 Formulação do roteiro semiestruturado e condução das entrevistas .......................................................................... 31

3.6 Tratamento e análise dos dados ........................................... 32

3.7 Limitações da abordagem de pesquisa ................................ 34

4 Resultados encontrados .................................................. 36

$4.1 \bigcirc$ trabalho remoto e sua necessidade em razão da pandemia .... 36

4.2 As categorias descritivas e as dimensões explicativas .............. 38

4.2.1 A preservação das rotinas ............................................... 41

4.2.2 A (re) organização da dimensão tempo-espaço ..................... 44

4.2.3 A capacidade de inovação ............................................... 49

$4.3 \bigcirc$ espaço de resultados ................................................. 54

4.3.1 A interpretação sintética do espaço de resultados ................. 54

5 Considerações finais ...................................................... 57 
6 Referências bibliográficas

62

Apêndice I - Roteiro semiestruturado

68

Apêndice II - Detalhamento dos sujeitos entrevistados no período de 14 de junho de 2020 a 21 de junho de 2020

Apêndice III - Detalhamento dos sujeitos entrevistados no período de 19 de outubro de 2020 a 23 de outubro de 2020 71 Apêndice IV - Lista de termos específicos 


\section{Lista de Figuras}

Figura 1: Relação entre os aspectos ostensivo e performativo e os artefatos 19

Figura 2: Centralidade dos artefatos nas rotinas organizacionais ...... 21

Figura 3: Tipologia de artefatos .................................................. 22

Figura 4: Representação de um frame de ferramentas culturais ........ 24

Figura 5: As etapas do método fenomenográfico ........................... 28

Figura 6: Organização hierárquica das categorias descritivas ........... 38

Figura 7: Correlação entre categorias descritivas e princípios subjacentes ....................................................................... 38 


\section{Lista de Quadros}

Quadro 1: Conceituação de artefatos e relação entre artefatos e

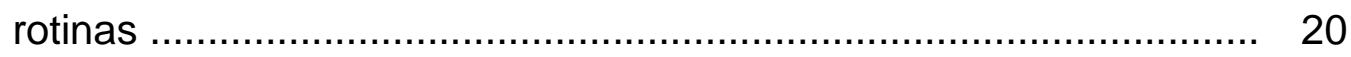

Quadro 2: Espaço de resultados ........................................ 51 
Na dialética da liberdade, o homem precisa sintetizar o necessário e o possível, e tanto o necessário quanto o possível variam através da história. Mas a sintetização sendo responsabilidade do próprio indivíduo existente, não há parâmetros fornecidos definitivamente. 


\section{0 problema de pesquisa}

A finalidade deste capítulo é apresentar o problema de pesquisa e as razões que motivaram a investigação do fenômeno. Para tanto, há uma introdução para contextualização do problema, culminando na questão central da pesquisa. Posteriormente, são apresentados os objetivos da pesquisa, suas delimitações e a relevância deste estudo no âmbito pessoal, social e para a comunidade acadêmica.

\subsection{Introdução}

Em dezembro de 2019, a China anunciava ao mundo os primeiros casos de pessoas infectadas pelo vírus SARS-CoV-2, doença que passou a ser conhecida como Covid-19, cujo nome faz referência à nomenclatura do vírus e ao ano em que foi verificada pela primeira vez pela comunidade científica (FIOCRUZ, 2020).

Pouquíssimo tempo depois, em 30 de janeiro de 2020, a Organização Mundial de Saúde - OMS declarou a Covid-19 como emergência de saúde pública de âmbito internacional (OMS, 2020) e, em 11 de março de 2020, a reconheceu como uma pandemia, que é caracterizada pela disseminação em escala global de uma nova doença, com transmissão sustentada de pessoa para pessoa. (OMS, 2020).

Considerando que a Covid-19 é uma infecção respiratória aguda, de elevada transmissibilidade e que pode levar a óbito, a Organização Mundial de Saúde apontou medidas de isolamento social como o principal meio para frear o contágio pelo vírus (OMS, 2020).

O Brasil, acompanhando a discussão que estava sendo travada internacionalmente, antes mesmo de confirmar seu primeiro caso, conferiu a cada chefe local do Poder Executivo - prefeitos e governadores - poderes para adotarem as medidas que entendessem cabíveis para preservar a população de suas regiões (BRASIL, 2020).

Na cidade do Rio de Janeiro, a partir de 16 de março de 2020, foram impostas restrições à circulação de pessoas, produtos e serviços e, em simultâneo, se pôs um enorme desafio às organizações: manter suas operações mesmo insertas no contexto pandêmico (ESTADO DO RIO DE JANEIRO, 2020). 
Dado este cenário, o presente estudo, partindo de um paradigma interpretativista e utilizando a fenomenografia como base metodológica (ARKELIND, 2005), intenta responder a seguinte pergunta de pesquisa: Como se deu a experienciação das rotinas organizacionais durante o período de isolamento social imposto pela pandemia da Covid-19?

\subsection{Relevância do estudo}

O desejo em responder como se deu a experienciação das rotinas organizacionais durante o período de isolamento social imposto pela pandemia da Covid-19 adveio da própria experiência pessoal da pesquisadora que, residente na cidade, não ficou alheia às medidas de isolamento social e aos impactos em suas rotinas. Assim, podese dizer que a auto-observação construiu o primeiro nível de relevância deste estudo: a relevância pessoal para a pesquisadora.

A partir do interesse particular, o SAR - Sistema Ativador Reticular, área do cérebro que faz com que a pessoa fique muito mais atenta às informações e oportunidades relacionadas ao que experiencia com frequência ou com forte impacto emocional (VIEIRA,2017), contribuiu para uma maior atenção da pesquisadora para todos os assuntos relacionados ao tema, incluindo comentários de profissionais sobre suas rotinas nas empresas em que trabalhavam, o que lançou luz sobre a existência de uma relevância social em torno da temática.

No que concerne à relevância para a comunidade acadêmica, as rotinas organizacionais têm sido objeto de investigação e de conceitualização há tempos (STENE,1940; MARCH e SIMON, 1958; CYERT, 1963; NELSON e WINTER, 1982), sendo possível considerar que as rotinas organizacionais passaram a ser reconhecidas como unidade de análise em 1982, com as contribuições de Nelson e Winter (1982).

Buscando uma conceitualização mais contemporânea, as rotinas organizacionais podem ser definidas como "padrões de ações interdependentes, reconhecíveis e repetitivos" (FELDMAN e PENTLAND, 2003, p.95) e que contam com a participação de múltiplos atores (FELDMAN e PENTLAND, 2005). Partindo dessa definição, estudos apontam que as rotinas organizacionais contribuem tanto para estabilidade, quanto para as mudanças que se visualizam dentro das organizações (PENTLAND e FELDMAN, 2005). 
Aproximando o conceito acima do desafio que se impôs às empresas - manter suas operações em funcionamento mesmo insertas no contexto pandêmico de isolamento social - é possível inferir que o presente estudo contribuirá academicamente com uma melhor compreensão sobre o quanto a dinâmica das rotinas organizacionais é relevante para garantir a manutenção o mais próxima possível do status quo ante ou para projetar inovações e diferenciação. (LEONARDI, 2011; EBERHARD et al., 2019; DANNER-SCHRÖDER \& GEIGER, 2016).

Além disso, poderá colaborar com o entendimento da relação entre a dinâmica das rotinas e a organização do tempo (TURNER \& RINDOVA, 2018) e entre a centralidade dos artefatos e a dinâmica das rotinas organizacionais (D’ADDERIO, 2008; D'ADDERIO, 2011).

Assim, o presente estudo, é sobretudo relevante, pois visa colaborar com a produção científica existente até então. Contudo, não será possível responder a todos os questionamentos que se porão ao longo da leitura, razão pela qual é indispensável a estabelecer os objetivos deste trabalho e delimitar seu escopo.

\subsection{Objetivos e delimitação do estudo}

O objetivo final desta fenomenografia é compreender como se deu a experienciação das rotinas organizacionais durante o período de isolamento social imposto pela pandemia da Covid-19.

Para alcançá-lo, no entanto, foi necessário estabelecer alguns objetivos intermediários, a saber:

- Revisar a evolução teórica e as discussões acadêmicas contemporâneas acerca das rotinas organizacionais;

- Analisar como os profissionais que colaboraram com a pesquisa significaram o fenômeno;

Apresentados os objetivos final e intermediário, importante esclarecer que esta pesquisa foi concebida sob um paradigma interpretativista (VERGARA e CALDAS, 2005) e valeu-se do método fenomenográfico (AKERLIND, 2005; MARTON, 1981).

Considerando que a realidade é uma construção social da qual a pesquisadora também participa (WALSHAM, 1993), é inafastável a compreensão de que, em certo ponto, a pesquisadora trouxe para o trabalho sua lente de observação do mundo, sendo que os resultados, no dizer de Saccol (2009), "não são os fatos em si 
(uma realidade objetiva), mas a interpretação do pesquisador sobre as interpretações dos indivíduos que participam em um determinado fenômeno".

Em última análise, este trabalho pretende observar o conjunto de significados que emergiu da experimentação do fenômeno pelos profissionais que contribuíram com a realização da pesquisa, tendo como ponto de partida a construção de um referencial teórico para melhor compreensão do que se apresentará, ao final, como espaço de resultados. 


\section{Referencial Teórico}

O espaço de resultados que será apresentado no capítulo 4 precisa ser suportado por um alicerce teórico que permita sua compreensão. Para tanto, este capítulo se ocupará de tal fim. Na primeira seção deste capítulo será exposta a conceituação de rotinas organizacionais à qual a pesquisadora se filia e o detalhamento de seus elementos. A seguir, na segunda seção, adentraremos na definição de artefatos, e em sua contribuição para a dinâmica das rotinas organizacionais. Na terceira seção, será possível visitar a relação existente entre rotinas organizacionais e a dimensão tempo-espaço e, por fim, na quarta seção, será explorada a relação entre rotinas organizacionais e a possibilidade (ou não) de criação de inovação.

\subsection{Rotinas Organizacionais}

As rotinas organizacionais têm sido objeto de investigação e de conceitualização desde o início do século passado (STENE,1940; MARCH e SIMON, 1958; CYERT e MARCH, 1963; NELSON e WINTER, 1982). No entanto, até Nelson e Winter (1982), as rotinas organizacionais eram analisadas como meio para atingir um determinado fim e não com fim em si mesmas, dessa forma, foi somente a partir dos estudos de Nelson e Winter (1982), que as rotinas organizacionais passaram a constituir, em si mesmas, objeto de análise.

Alcançada a autonomia enquanto objeto de pesquisa, os pesquisadores passaram a fazer suas análises a partir de duas premissas diversas: ou as rotinas organizacionais serviam ao propósito das organizações e, nesse sentido, eram concebidas e gerenciadas pela própria empresa (PARMIGIANI e HOWARDGRENVILLE, 2011); ou por uma perspectiva prática em que os sujeitos tinham fundamental influência e interferência na execução das rotinas e em seus resultados, emergindo conceitualmente o que atualmente compreendemos como aspectos ostensivo e performativo das rotinas organizacionais (FELDMAN, 2000; FELDMAN e PENTLAND, 2003). Aos aspectos ostensivo e performativo, somaram-se os artefatos (D’ADDERIO, 2003) que, para alguns, alcança status de epicentro na dinâmica das rotinas (D’ADDERIO, 2008).

O conceito de rotinas organizacionais ao qual a pesquisadora se filia é no sentido de que se trata de "padrões de ações interdependentes, reconhecíveis e 
repetitivos" (FELDMAN e PENTLAND, 2003, p.95) e que contam com a participação de múltiplos atores (FELDMAN e PENTLAND, 2005).

Feita essa breve digressão, importante adentrar na definição dos aspectos ostensivo e performativo das rotinas organizacionais.

\subsubsection{Aspectos ostensivo e performativo}

Retomando o conceito de rotinas organizacionais: "conjunto de ações, repetitivas, reconhecíveis e desempenhadas por múltiplos atores" (FELDMAN e PENTLAND, 2003; FELDMAN e PENTLAND, 2005), se isolarmos o termo "repetitivas", nos aproximaremos do aspecto ostensivo.

O aspecto ostensivo é como o "dever ser" de Kant (1980): aja sempre da maneira que fora predeterminado abstratamente. Nesse sentido, o aspecto ostensivo é uma a cadeia de ações repetidas contínuas vezes, por um grupo de indivíduos (FELDMAN e PENTLAND, 2003).

A concepção sobre a rotina pode ocorrer mental e abstratamente pelos próprios indivíduos (FELDMAN e PENTLAND, 2003) ou pode ser dada pela própria organização (PARMIGIANI e HOWARD-GRENVILLE, 2011) e seguida pelos indivíduos.

O mero ato de seguir, por si, também configura o aspecto ostensivo (FELDMAN e PENTLAND, 2005), na medida em que esta ação servirá de amparo para o desempenho da rotina, inalterada, por novos indivíduos que integrarão o grupo, perpetuando-a.

Nesse sentido, o aspecto ostensivo relaciona-se à estabilidade das rotinas organizacionais e admite que ocorram mudanças exógenas nas rotinas.

Assim, a interpretação das rotinas organizacionais unicamente por este viés contribuiu para um equivocado entendimento em que o vocábulo rotina remete à sensação de inflexibilidade e paralisia, o que não configura uma verdade para a perspectiva prática das rotinas organizacionais, uma vez que a existência da rotina organizacional depende também da presença do aspecto performativo, de forma que pela lente teórica adotada por este estudo, o aspecto ostensivo por si, não pode ser confundido com o conceito de rotina organizacional (FELDMAN e PENTLAND, 2005).

Para adentrar na análise do aspecto performativo, importante retomar uma vez mais o conceito de rotinas organizacionais apresentado por Feldman e Pentland 
(2003): "conjunto de ações, repetitivas, reconhecíveis e desempenhadas por múltiplos atores", e ao isolar o termo "reconhecíveis", haverá aproximação do aspecto performativo.

$\mathrm{O}$ ato de reconhecer está intimamente ligado a uma percepção subjetiva e, nesse sentido, pode variar para cada um dos atores envolvidos na rotina, isto é, a partir de uma análise individual do aspecto ostensivo de determinada rotina, o indivíduo irá modular seu desempenho de acordo com a representatividade subjetiva daquela rotina para si (FELDMAN, 2003).

Temos, portanto, que o aspecto performativo se relaciona com a atividade em si, com a performance. Aqui cabe uma intervenção relevante: a variância de performance, per se, não representa alteração da rotina. Porém, é no aspecto performativo que se visualiza o locus da mudança endógena das rotinas (FELDMAN et al.; 2016; FELDMAN \& PENTLAND, 2003).

Importante ressaltar que tanto para o aspecto ostensivo, quanto para o aspecto performativo, não raro, há uma intenção das organizações em capturar sua essência em artefatos, como manuais, por exemplo. No entanto, com relação ao aspecto performativo das rotinas organizacionais há uma limitação de retenção que não pode ser ignorada, uma vez que grande parte de sua existência depende da própria atuação dos participantes que ocorre de forma recorrente (FELDMAN e PENTLAND, 2005).

Uma vez apresentados os aspectos ostensivo e performativo das rotinas organizacionais, passaremos à análise dos artefatos que, reconhecidamente, são parte integrante das rotinas organizacionais (FELDMAN e PENTLAND, 2005).

\subsubsection{Artefatos}

$\mathrm{Na}$ perspectiva prática das rotinas organizacionais, o aspecto ostensivo funciona como padrão abstrato a ser adotado, ao passo que o aspecto performativo decorre da percepção subjetiva do aspecto ostensivo, valorando-o. No entanto, não são os únicos elementos a serem observados quando da análise das rotinas organizacionais, sendo indispensável considerar os artefatos como parte integrante desta dinâmica (FELDMAN e PENTLAND, 2005), como se depreende da figura 1. 


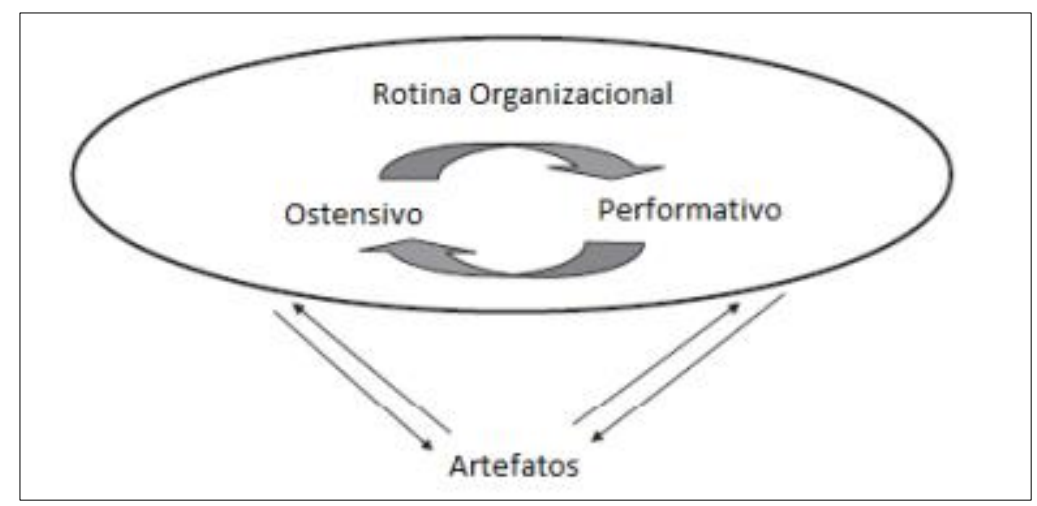

Figura 1: Relação entre os aspectos ostensivo e performativo e os artefatos Fonte: Feldman e Pentland (2005)

Para D’adderio (2011), artefatos são qualquer coisa feita pela arte humana, geralmente para um propósito prático, ou seja, são uma criação humana que visam contribuir com a cognição sobre algo.

Em sua ampla maioria, as organizações visam codificar os aspectos ostensivo e performativo e se valem dos artefatos para fazê-lo, em uma tentativa de transformar o artefato em uma proxy da rotina (FELDMAN e PENTLAND, 2005).

Nesse sentido, os artefatos mais comuns são aqueles que visam capturar ou prescrever uma dada rotina, como por exemplo manuais; procedimentos operacionais padronizados (SOP); fluxogramas e outros, que podem ser utilizados de forma física ou incorporados a alguma tecnologia como softwares, por exemplo (FELDMAN e PENTLAND, 2005).

Nota-se, então, que o artefato não é a rotina em si, mas apenas uma aproximação desta e, assim, forçoso reconhecer sua limitação, haja vista que, embora criado para estabelecer e reproduzir padrões, os atores das rotinas acrescentam-lhe constantemente variações (PENTLAND e FELDMAN, 2005).

Assim, a compreensão do artefato enquanto tal e a identificação da relação do artefato com a rotina não é singela e guarda três perspectivas (D’ADDERIO, 2011), conforme se observa no quadro 1 abaixo. 


\begin{tabular}{|l|l|}
\hline \multicolumn{1}{|c|}{$\begin{array}{c}\text { Perspectiva para conceituação dos } \\
\text { artefatos }\end{array}$} & \multicolumn{1}{|c|}{$\begin{array}{c}\text { Relação entre artefatos e rotinas } \\
\text { organizacionais }\end{array}$} \\
\hline $\begin{array}{l}\text { Realista: artefatos são coisas com } \\
\text { probidades estáticas (MUMFORD, 1964; } \\
\text { WINNER, 1980) }\end{array}$ & $\begin{array}{l}\text { Memória externa: artefatos se prestam a } \\
\text { auxiliar humanos a solucionar problemas } \\
\text { complexos (NELSON E WINTER, 1982) }\end{array}$ \\
\hline $\begin{array}{l}\text { Construtivista: artefatos não tem } \\
\text { propriedades objetivas e são fruto da } \\
\text { interpretação humana (PINCH e } \\
\text { BIJKER, 1987) }\end{array}$ & $\begin{array}{l}\text { Proxy da rotina: artefatos não são a própria } \\
\text { rotina e é a rotina quem estabelece a } \\
\text { performatividade e não o artefato } \\
\text { (FELDMAN e PENTLAND, 2005) }\end{array}$ \\
\hline $\begin{array}{l}\text { ANT: artefatos são fruto de uma co- } \\
\text { construção entre elementos técnico e e } \\
\text { humanos (CALLON E CALISKAN, } \\
\text { 2010) }\end{array}$ & $\begin{array}{l}\text { Centralidade dos artefatos: artefatos são } \\
\text { verdadeiros mediadores entre agências e, } \\
\text { dessa forma, são produzidos e reproduzidos } \\
\text { enquanto a rotina se desenvolve } \\
\text { (D'ADDERIO, 2011) }\end{array}$ \\
\hline
\end{tabular}

Quadro 1: Conceituação de artefatos e relação entre artefatos e rotinas

Fonte: Elaborado pela autora

A figura 2, demonstra a evolução da concepção do artefato como elemento da rotina para a concepção do artefato como centro da rotina.

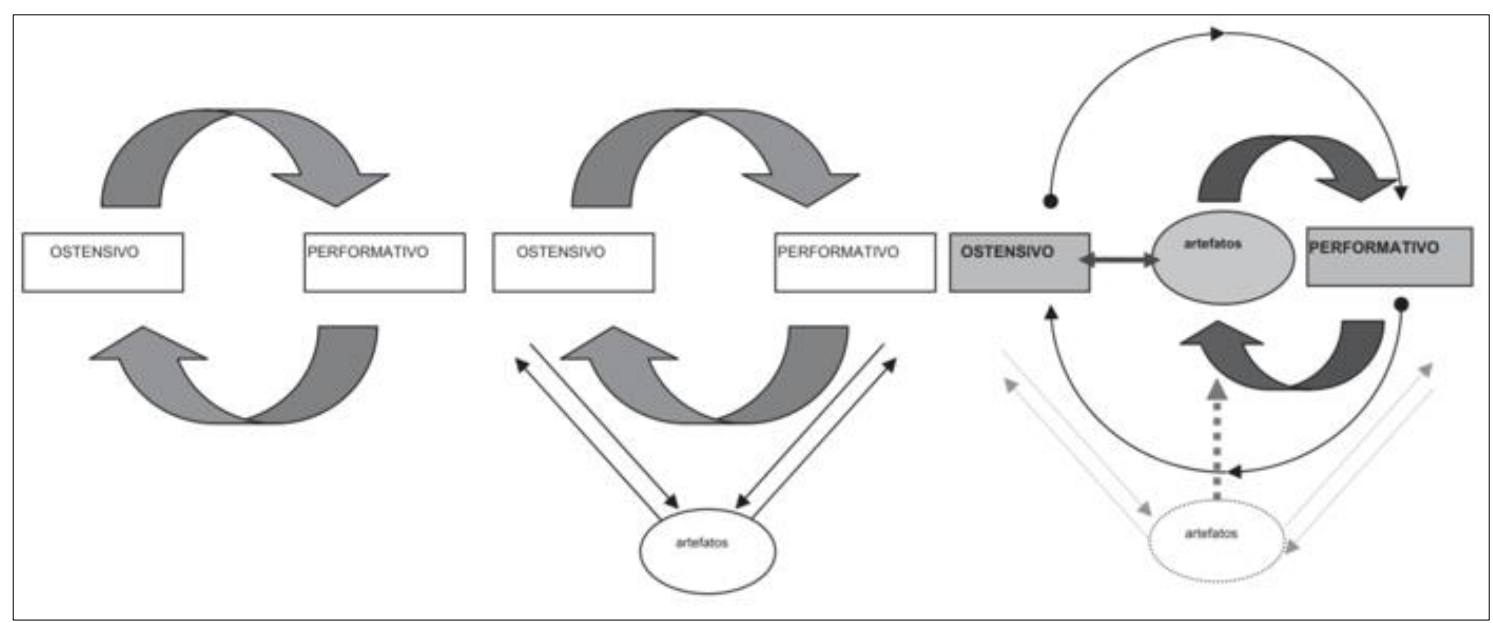

Figura 2: Centralidade dos artefatos nas rotinas organizacionais Fonte: D'adderio, (2011)

Uma das implicações imediatas do reconhecimento da centralidade dos artefatos é que eles podem moldar ativamente o curso das rotinas e influenciar diretamente na configuração do poder de agência entre os atores envolvidos (D'ADDERIO, 2011). Além disso, nessa estrutura, os artefatos representam linguagem expressa e simbólica que contribuem para a transmissão da mensagem (D’ADDERIO, 2011).

Especificamente quanto à relação entre artefatos e disputa pelo poder de agência, Cacciatori (2012) desenvolveu uma tipologia de artefatos composta por quatro categorias que se relacionam entre si e que, se observadas em matriz, demonstram quando é maior ou menor a capacidade de geração de soluções bem 
como maior ou menor a disputa pelo poder de agência. As categorias são: $1^{\text {a }}$ ) Artefatos que falam, são aqueles que contêm representações de conhecimento textual ou visual, por exemplo, manuais; $2^{\mathrm{a}}$ ) Artefatos silenciosos, não contem representação cognitiva isolada mas possuem conteúdo simbólico se contextualmente interpretados, mobília; $3^{\mathrm{a}}$ ) Artefatos específicos para ocupação, são relacionados às ferramentas necessárias ao desempenho de uma atividade específica, por exemplo, manual de desenho e mesa de desenho; $4^{\mathrm{a}}$ ) Artefatos genéricos para ocupação, podem ser utilizados por todas as pessoas independente da atividade, por exemplo, computador. A figura 3 apresenta a matriz proposta pela autora.

\begin{tabular}{|c|c|l|l||}
\hline \multicolumn{4}{|c|}{ Potencial de conflitos } \\
\cline { 2 - 5 } & \multicolumn{1}{|c|}{ Ocupação genérica } & \multicolumn{1}{c|}{ Ocupação específica } \\
\cline { 2 - 5 } $\begin{array}{c}\text { Potencial } \\
\text { de } \\
\text { solução } \\
\text { de } \\
\text { problemas }\end{array}$ & Silencioso & $\begin{array}{l}\text { Mobiliário, layout das salas, } \\
\text { portas abertas e fechadas }\end{array}$ & $\begin{array}{l}\text { Ferramentas } \\
\text { estetoscópio), protótipos } \\
\text { físicos }\end{array}$ \\
\cline { 2 - 5 } & Falante & $\begin{array}{l}\text { Relatórios, procedimentos } \\
\text { organizacionais }\end{array}$ & $\begin{array}{l}\text { Procedimentos profissionais, } \\
\text { desenhos protótipos virtuais }\end{array}$ \\
\hline
\end{tabular}

Figura 3: Tipologia de Artefatos

Fonte: Cacciatori (2012).

Da análise da matriz proposta por Cacciatori (2012), observa-se que, quanto mais falante o artefato, maior sua capacidade de configurar solução para problemas; ao passo que quanto mais específica for sua ocupação, maior será a possibilidade de haver conflito entre atores disputando pela agência na configuração ou reconfiguração dos artefatos.

$\mathrm{Na}$ qualidade de artefato, a tecnologia tem se apresentado um importante mediador das rotinas organizacionais, independentemente da natureza da atividade (MANSELL et al.; 2007) e, além de agregar para concepção e controle de metas, por exemplo, ainda apresenta outros benefícios, dentre os quais é possível mencionar uma maior integração da comunicação dos atores relacionados (COOMBS, 2015), o que reforça a relação recursiva entre a agência material do artefato e a agência humana. 


\subsubsection{Rotinas organizacionais e dimensão tempo-espaço}

"A agência humana (social) e a agência material (artefatos) se manifestam no espaço social influenciando a dinâmica das práticas sociais" (BERENGER et al.; 2019, p. 8). Ainda segundo os autores, se de um lado a agência humana relacionase à capacidade de o ator refletir, agir e reconfigurar padrões; de lado outro a agência material relaciona-se à influência dos artefatos nas práticas sociais, o que viabiliza ou restringe a agência humana em uma dada circunstância (LEONARDI, 2011). A relação entre o humano e o material é complexa e ocorre circunscrita em tempo e espaço.

Essa relação conhecida como sociomaterialidade sustenta a existência de diálogo entre artefatos e pessoas sem que haja primazia de um ou outro (SUCHMAN, 2002; LEONARDI, 2011), uma vez que pessoas necessitam de artefatos para realizar suas práticas e artefatos precisam de pessoas que lhes atribuam sentido (LEONARDI, 2012).

Tanto a execução das rotinas, quanto os artefatos relacionados são mantidos (fonte de estabilidade) ou alterados (fonte de mudança) em atenção às oportunidades ou limitações impostas pelo contexto, o que favorece a compreensão de que tanto a rotina quanto o artefato estão circunscritos em um determinado tempo e espaço (LEONARDI, 2011).

Segundo Hawking (1988, p. 60), "o espaço e o tempo não apenas afetam, mas também são afetados por qualquer coisa que aconteça no universo". Com os espaços sociais não seria diferente e, por isso, são construídos objetiva e subjetivamente, em relação recursiva com o tempo (VERGARA, 2005).

Segundo Vergara (2005), a sociedade atual, modelada especialmente a partir dos anos 90 do século $\mathrm{XX}$, tem na dimensão de tempo-espaço sua variável de primeira instância: tornou-se uma categoria única que busca garantir eficiência e produtividade, causando a percepção de que o tempo está sendo acelerado e os espaços encurtados.

Dito isso, uma vez que as rotinas organizacionais acontecem circunscritas no tempo-espaço, estruturas, processos, tomadas de decisão, são diretamente influenciados pelo contexto e podem interferir no processo de inovação das organizações. 


\subsubsection{Rotinas organizacionais e inovação}

Em Leonardi (2011), é possível observar que estudiosos sugerem que a discrepância entre grupos envolvidos no desenvolvimento de tecnologia pode ser rastreada por meio de diferenças culturais. Nesta senda, na mesma obra, o autor faz uma alusão a atores, todos com acesso ao mesmo estoque de ferramentas culturais e prossegue afirmando que para o desenvolvimento de um trabalho específico, será necessária apenas uma parcela delas, não todas. A escolha das ferramentas é feita pelos próprios atores e, para explicar como se dá esse processo, Leonardi (2011) se utiliza do conceito de "frames".

A ideia de "frames" ajuda a explicar o porquê de grupos de pessoas compartilharem acesso ao mesmo conjunto de ferramentas de recursos culturais e, mesmo assim, poderem agir e inferir no mundo de maneiras diferentes. A figura 4 demonstra a dinâmica.

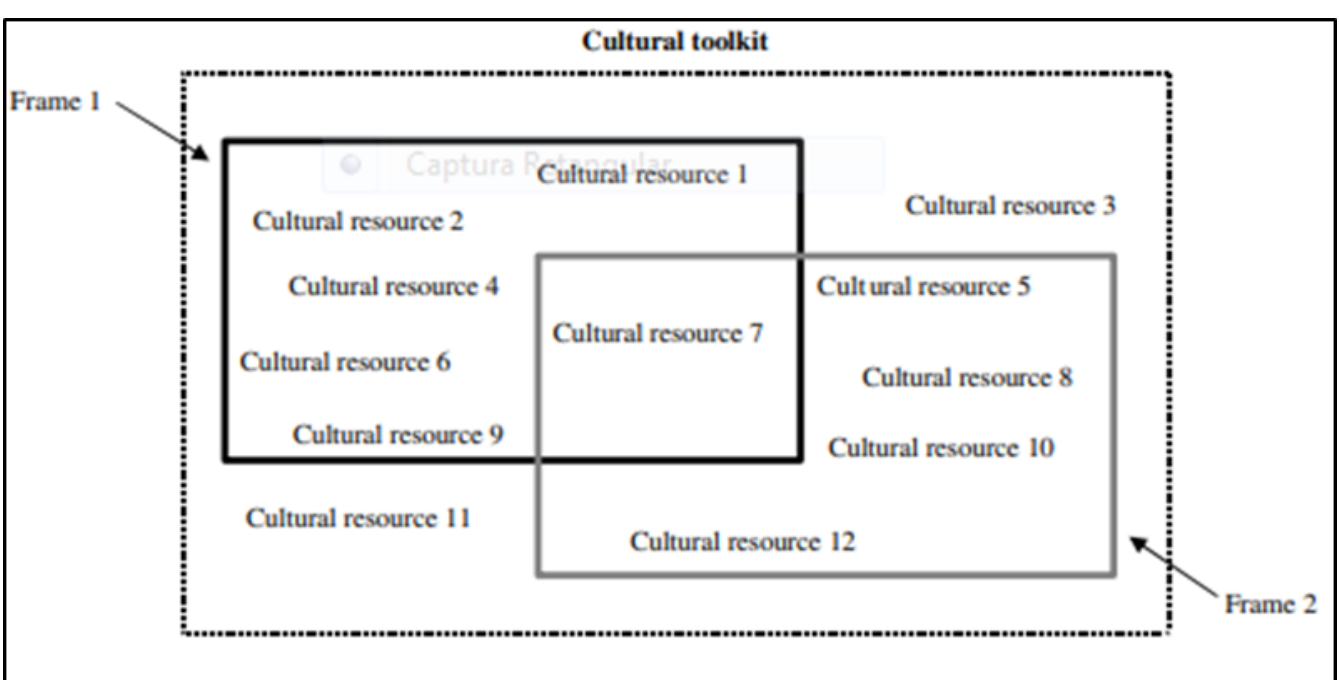

Figura 4: Representação de um kit de ferramentas cultural.

Fonte: LEONARDI, (2016).

Depreende-se da figura 4 que o total de ferramentas culturais disponíveis na organização é representado pela caixa pontilhada. Já os “frames" são as caixas preta e cinza. Em cada uma das caixas (frames), há apenas algumas das ferramentas culturais disponíveis no todo, que podem ser utilizadas de forma compartilhada, ou não. A disposição desses recursos pode ocasionar estratégias diferenciadas de comportamento em toda a organização (LEONARDI, 2011).

Nas fases iniciais do processo de inovação, cultura e a tecnologia podem não ser empiricamente distinguíveis (LEONARDI, 2011). Isso porque, na abordagem 
de "tecnologia como estrutura" os conceitos tecnológicos são apresentados como os principais meios pelos quais os recursos culturais estarão alinhados às estratégias de ação. Já na abordagem de tecnologia como inovação, os atores usam seus recursos culturais para refinar os problemas e sua conceituação de mudanças tecnológicas para poder resolver esta dificuldade. Desta forma, conceitos tecnológicos podem ser usados para escolher ativos culturais que influenciam os artefatos tecnológicos que eventualmente serão construídos. Nesta segunda abordagem, tecnologia e cultura são indistinguíveis (LEONARDI, 2011).

O conceito de tecnologia tornou-se, então, uma proxy para inovação, de forma que debates sobre artefatos tecnológicos se tornaram debates sobre como os valores culturais se põe sobre problemas no processo de inovação. (LEONARDI, 2011).

Tangencia a discussão sobre inovação a questão da criatividade. George (2007, p. 444) descreve a criatividade como "imprevisível" e como tendo "o potencial para níveis mais baixos de previsibilidade" e confiabilidade. Para Sonenshein (2016), esta visão fortalece a dualidade entre procedimentos (que os cientistas costumam dizer que aumentam a confiabilidade) e criatividade (que os estudiosos costumam dizer que é prejudicial confiabilidade).

Uma abordagem que trata a rotina e a criatividade como dualidade incentiva uma separação entre ambos, porém, salvo melhor juízo, ignora amplamente os processos criativos (SONENSHEIN, 2016).

Cohendet e Simon (2016) apontam para a possibilidade de, valendo-se da criatividade, em um cenário de crise, um novo padrão de rotina se construir e sugerem que uma maneira de atingir esse equilíbrio é destruir, dividir e reorganizar deliberadamente vários aspectos das rotinas vigentes (COHENDET; SIMON, 2016).

Definir quando reorganizar deliberadamente os aspectos das rotinas ainda é um desafio para as organizações e, nesse sentido, essa reengenharia pode também ser motivada por razão externas, dentre as quais pode citar a eclosão de desastres naturais (FELDMAN et al.; 2013) ou o surgimento de uma novidade ou inovação radical (DEKEN et al.; 2013).

Havida uma motivação externa para mudança, e no contexto deste estudo a pandemia da Covid-19 pode ser considerada como tal, algumas questões são postas em xeque para as empresas, como por exemplo: reconstruir partes de rotinas (COHENDET; SIMON, 2016); promover recombinação entre rotinas 
(D'ADDERIO E POLLOCK, 2014), equilibrar eficiência e flexibilidade (HOWARD-GRENVILLE, 2005) reconfigurar as formas de obtenção de recursos (FELDMAN, 2004).

Independentemente de se encontrarem em um cenário de crise, as organizações atuais enfrentam desafios que, segundo Vick et al. (2015) se distribuem em quatro eixos principais: $1^{\circ}$ ) o desafio da inovação estratégica; $2^{\circ}$ ) buscar vantagens competitivas por meio do desenvolvimento e reconfiguração de habilidades dinâmicas; $3^{\circ}$ ) a necessidade de articulação e assimilação de conhecimentos voltados para a aprendizagem e $4^{\circ}$ ) o desafio de compreender e dar sentido ao contexto organizacional experiência subjetiva (simbolismo) da organização e seus membros.

O primeiro destes desafios, que é a inovação estratégica, requer a adaptação contínua das organizações que podem ser promovidas em termos de produtos, serviços, operações, processos e pessoas.

No contexto pandêmico, talvez o desafio mais emergente, por uma necessidade natural majorada pela situação de crise, tenha sido o da inovação estratégica, uma vez que, antes de qualquer outro objetivo, as empresas apenas tinham que se manter em funcionamento em um momento em que a configuração das rotinas que eram praticadas não atendiam ao contexto.

A imposição do teletrabalho fez com que, no mínimo, as ações concebidas por seus atores como rotinas organizacionais fossem revisitadas e adaptadas para execução de forma remota. Tudo isso num lapso temporal muito exíguo, o que implicou em algumas empresas que apenas conseguiram transpor suas rotinas do espaço físico para o virtual, e em outras que de fato conseguiram promover inovação, conforme será apresentado no espaço de resultados. 


\section{Procedimentos Metodológicos}

Uma vez delineado o referencial teórico, importante incursionar pela metodologia científica que amparou a pesquisa. Diante disso, esse capítulo tem como objetivo central explicar o método fenomenográfico e justificar sua escolha. O capítulo está dividido em seções que tratam, respectivamente, dos aspectos epistemológicos e ontológicos, do tipo de pesquisa e sua justificativa de escolha, da seleção dos sujeitos e da coleta de dados, do tratamento dos dados e, por fim, das limitações da abordagem de pesquisa.

\subsection{Aspectos epistemológicos e ontológicos}

De modo a alcançar o objetivo deste estudo, será utilizada a pesquisa qualitativa. De acordo com Creswell (2010), essa abordagem se dá no ambiente em que ocorre o fenômeno sob investigação e analisa os significados que os atores atribuem ao evento que experienciaram. Ao considerar signos construídos a partir da relação recursiva entre sujeito e objeto, é possível afirmar que este estudo considerará que a realidade se constrói a partir desta interação (ORLIKOWSKI e BAROUDI, 1991), ou seja, valer-se-á de um paradigma interpretativista.

A epistemologia interpretativista é, na essência, construtivista, isto é, parte da premissa de que a realidade é a exteriorização da prática humana e de sua interação com o mundo (SACCOL, 2009). Assim, é possível inferir que a realidade é uma construção social da qual o pesquisador também participa (WALSHAM, 1993), apresentando-se, nesse sentido, o desafio de o pesquisador ir a campo mantendo o máximo de neutralidade possível para dar voz aos participantes da pesquisa e não para utilizá-los como veículo de exteriorização de convicção própria (ORLIKOWSKI e BAROUDI, 1991).

Feita essa digressão sobre ontologia e epistemologia de pesquisa, passa-se a discorrer sobre o plano de ação (método) para materializar objetivo da pesquisa.

\subsection{Método Fenomenográfico}

Dentre os diversos métodos qualitativos disponíveis, para a consecução deste trabalho, foi utilizada a fenomenografia, que, em estreita síntese, visa alcançar as concepções dos sujeitos sobre um dado fenômeno (MARTON,1986). Esse método foi incialmente aplicado no contexto escolar (MARTON,1986) e, passou a 
ser utilizado também em estudos organizacionais no início da década de 1990 (SANDBERG,1991).

A Fenomenografia pode focar na análise de relatos sobre um fenômeno e, nesse caso, a centralidade estará no fenômeno em si (MARTON e BOOTH, 1997); quanto pode buscar identificar as experiências das pessoas que vivenciaram o fenômeno (MARTON, 1981).

Tendo em vista que este trabalho se centra no objetivo de identificar que, sujeitos, expostos ao mesmo fenômeno, podem o compreendê-lo de formas diversas (CHERMAN; ROCHA-PINTO, 2015), este estudo vale-se da perspectiva fenomenográfica de segunda ordem (MARTON, 1981).

Em síntese, são quatro as etapas do método fenomenográfico: eleição dos sujeitos; realização das entrevistas (coleta de dados), análise dos dados e identificação dos significados-padrão encontrados na análise (SANTOS et al.; 2018).

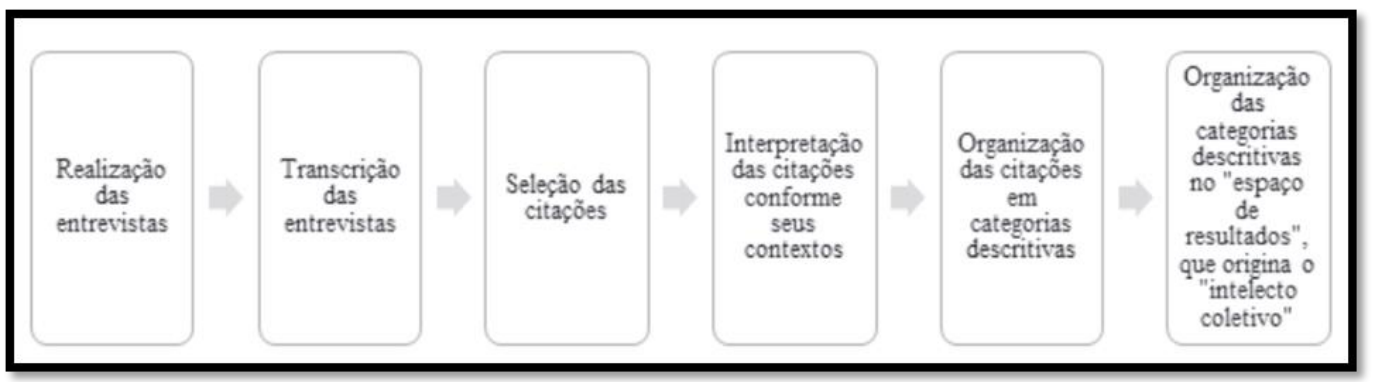

Figura 5: As etapas do método fenomenográfico.

Fonte: SANTOS, 2018.

Talvez, o mais desafiador da terceira etapa seja proceder com a despersonificação dos sujeitos para que a fala de cada um passe a integrar um coletivo de significados (MARTN,1986) e seja construir uma reflexão sobre os dados o mais isenta possível.

Tendo em vista que o presente estudo é focado nas experiências dos profissionais que experienciaram o isolamento social imposto pela pandemia da COVID-19, a abordagem Fenomenográfica pareceu à pesquisadora a mais adequada frente ao problema de pesquisa, conforme demonstrar-se-á a seguir.

\subsection{Justificativa para adoção da abordagem fenomenográfica}

Considerando que a fenomenografia pretende mapear as relações entre os diferentes significados ou maneiras de vivenciar o fenômeno (ARKELIND, 2005), 
essa abordagem trouxe uma visão holística frente aos relatos, suportando o objetivo de pesquisa, ou seja, proporcionou à pesquisadora meios de investigar a experiência coletiva quanto ao fenômeno de maneira abrangente, sem desprezar a experienciação individual de cada um dos entrevistados (SANDBERG, 2000).

Também contribuiu para a escolha da fenomenografia o reconhecimento do método como adequado apara analisar fenômenos experienciados por uma população específica de sujeitos (BOWDEN e WALSH, 2000), que no caso é consubstanciada por profissionais que estavam em plena atividade profissional na quando foram adotadas medidas de isolamento social.

Acrescenta-se aos pontos já expostos o fato de que, mesmo já contando mais de 30 anos desde a primeira pesquisa Fenomenográfica aplicada à área de organizações, ainda se considera tímida a produção de pesquisa valendo-se deste método (CHERMAN; ROCHA-PINTO, 2015), sendo esta uma oportunidade de contribuir para a difusão do método no que tange aos estudos organizacionais.

\subsection{Seleção dos sujeitos e coleta de dados}

É próprio do método fenomenográfico garantir a variação de sujeitos (BOWDEN, 2005) e considerar como ideal um número de entrevistados entre $20 \mathrm{e}$ 30 pessoas, (BOWDEN \& GREEN, 2005).

A fim de atender aos pressupostos do método, a pesquisadora, inicialmente, selecionou 40 sujeitos, já considerando possíveis eventualidades que inviabilizassem a participação de alguns deles da pesquisa.

Todos os 40 sujeitos selecionados estavam desenvolvendo atividade laboral em 16 de março de 2020, quando foi determinado o isolamento social na cidade do Rio de Janeiro, e seguiram em seus postos de trabalho durante o isolamento e, portanto, estavam trabalhando no momento da realização da entrevista.

Para atender ao critério de variedade, a pesquisadora, intencionalmente, escolheu pessoas que trabalhassem em diferentes organizações ou, caso trabalhassem na mesma empresa, preocupou-se que ocupassem diferentes cargos e exercessem diferentes funções. Além disso, cuidou para que os sujeitos guardassem diversidade de gêneros; idades; formação; tempo de experiência profissional e tempo de empresa. 


\subsection{Formulação do roteiro semiestruturado e da condução das entrevistas}

Após a elaboração da listagem inicial dos sujeitos elegíveis para colaborar com a pesquisa, a pesquisadora elaborou um roteiro de entrevistas semiestruturado (Apêndice I).

A parte inicial do roteiro foi composta por uma breve apresentação de como se daria a entrevista e para que finalidade seria utilizada, sempre adotando a cautela de requerer expressamente a autorização para gravação do material.

Feita a apresentação, seguia-se para a etapa de perguntas introdutórias cujo objetivo era garantir o pressuposto de variedade de sujeitos exigido pelo método fenomenográfico.

Após essa etapa, iniciava-se a contextualização do problema de pesquisa e advinha, então, a pergunta central da pesquisa: Dado o contexto pandêmico e o contexto de isolamento social, eu gostaria que você me contasse como você tem experienciado suas rotinas organizacionais?

O objetivo era de que o entrevistado falasse livremente sobre sua experiência, apresentando exemplos e expondo suas sensações, sentimentos e percepções relacionados ao fenômeno.

Resguardando a mínima interferência da pesquisadora, o roteiro semiestruturado contemplou perguntas acessórias. Curtas, diretas, muitas vezes compostas por uma única palavra, tudo com a finalidade de estimular que o entrevistado de fato mergulhasse em suas experienciação e permitisse que a pesquisadora o acompanhasse.

Ao final, o roteiro guardou um espaço para que o entrevistado pudesse fazer mais alguma consideração ou ponderação sobre o assunto.

Com a finalização do roteiro semiestruturado e com a lista preliminar de pessoas elegíveis à participação na entrevista, a pesquisadora passou a fazer contato por telefone, e-mail e mensagens instantâneas com os sujeitos para marcar data e horário para realização das entrevistas.

Embora no período em que as entrevistas foram realizadas as pessoas já estivessem podendo circular a despeito da permanência da pandemia, muitas ainda estavam trabalhando exclusivamente de casa e outras não se sentiam confortáveis para realizar outro trajeto que não casa $\mathrm{x}$ trabalho $\mathrm{x}$ casa, razão pela qual as 
entrevistas foram realizadas por telefone e tiveram o áudio gravado e posteriormente transcrito.

Do grupo inicialmente selecionado (40 profissionais), apenas 30 pessoas participaram efetivamente da pesquisa, sendo 20 delas no período de 14 de junho de 2020 a 21 de junho de 2020 (Apêndice II), e outras 10 no período compreendido entre 19 de outubro de 2020 a 23 de outubro de 2020 (Apêndice III).

No primeiro período de entrevistas foram 763 minutos de áudio gravado e no segundo período foram 378 minutos, totalizando 1141 minutos de gravações.

Durante as entrevistas os sujeitos permaneceram à vontade e dispostos a contribuir com o estudo. A pesquisadora acredita que o fato de não trabalhar na mesma organização de nenhum dos sujeitos tenha colaborado para que suas experiencias tenham sido detalhadas sem qualquer desconforto.

Realizadas todas as 30 entrevistas, a pesquisadora passou ao tratamento dos dados e sua análise.

\subsection{Tratamento dos dados e análise dos dados}

Os 30 relatos totalizaram 447 páginas transcritas. Com as transcrições organizadas em arquivo digital, a pesquisadora despersonificou os entrevistados, excluindo das transcrições a alusão aos seus nomes. Substituiu o nome dos entrevistados por um número de 1 a 30. Incluiu uma codificação de 'grupo 1" para as entrevistas realizadas entre de 14 de junho de 2020 e 21 de junho de 2020 e de “grupo 2" para as entrevistas realizadas entre 19 de outubro de 2020 a 23 de outubro de 2020.

Em atenção à orientação de Marton (1981), que esclarece que na fenomenografia as experiencias que emergem não são avaliadas individualmente, mas sim a partir da visualização de um conjunto de significados similares, a pesquisadora passou a fazer a leitura do material e destacar em diferentes cores as experiências que se aproximavam entre si.

Durante esse processo inicial, a pesquisadora observou que os relatos que integravam o "grupo 2" (Apêndice III) tratavam o fenômeno sob outro prisma: enquanto as entrevistas do "grupo 1" apresentavam claramente as ideais e experiências dos entrevistados sobre o fenômeno; os relatos do "grupo 2" traziam 
meros relatos acerca do fenômeno. Enquanto o primeiro grupo relatava experiências, o segundo grupo apresentava informações sobre o fenômeno.

Foi então que a pesquisadora identificou que as entrevistas do "grupo 2" desconsideravam as concepções dos indivíduos e intentavam uma tradução quanto à natureza aparente do fenômeno (MARTON, 1981).

Nesse ponto, convém rememorar os ensinamentos de Marton \& Booth (1997), no sentido de que, como não há meios de fazer uma descrição absolutamente completa de dada experiência, a fenomenografia chama de consciência focal a experienciação de um dado fenômeno a partir de um ponto relevante para o indivíduo que o concebe (MARTON \& BOOTH, 1997).

De acordo com Marton \& Booth (1997), não são todos os aspectos relevantes de um fenômeno que são apresentados simultaneamente, de forma que algum aspecto predominante da vivência assume a consciência focal.

Para o primeiro grupo de entrevistados, a consciência focal estava na experiência, ao passo que para o segundo grupo de entrevistados a consciência focal estava em descrever o fenômeno. Por essa razão, todas as entrevistas do "grupo 2" (Apêndice III) foram desconsideradas para fins de construção do espaço de resultado.

Tomada esta difícil decisão, porém amparada pela literatura relacionada ao método fenomenográfico, a pesquisadora apagou todas as marcações em cores inicialmente realizadas e recomeçou a leitura de todas as entrevistas do "grupo 1" (Apêndice II) e passou a fazer novas marcações em cores distintas com o objetivo de identificar as categorias representativas da sinergia entre os discursos similares.

Em um primeiro momento, foram identificados 10 grupos de assuntos: centralidade dos artefatos, apropriação de rotinas de outros atores, reconfiguração do tempo-espaço, compressão do tempo-espaço, imposição de desenvolvimento técnico-comportamental; questionamento às relações de confiança, condições emocionais como agenda, aceleração do processo decisório, repactuação de bases contratuais e inoperância de rotinas.

Uma segunda leitura trouxe a perspectiva de que esses grupos de assuntos configuravam dimensões explicativas e que poderiam ser agrupados em 4 dimensões: dinamismo dos componentes operativos das rotinas, aspectos técnicoscomportamentais dos atores envolvidos, aspectos gerenciais sobre as rotinas e percepção de segurança. 
A fim de confirmar o referido insight, a pesquisadora realizou uma terceira leitura do material e buscou responder à seguinte pergunta: "O que" isso me esclarece sobre a forma como esse entrevistado compreendeu suas rotinas organizacionais durante o período de isolamento social imposto pela pandemia da COVID-19? (AKERLIND, 2005).

As dimensões explicativas foram confirmadas e emergiram as categorias descritivas que consolidaram as experiencias comuns, agrupando-as e buscando estabelecer entre tais grupos uma relação de hierarquia (ARKELIND, 2005).

Ao final da análise, a pesquisadora se deparou com três categorias descritivas e quatro dimensões explicativas. Todas serão objeto de detalhamento no capítulo 4.

Importante ressaltar, no entanto, que a detida aplicação do método fenomenográfico não transformou a pesquisadora em um ser cem porcento imparcial diante dos dados, especialmente porque a pesquisadora também experienciou o fenômeno, sendo esta uma das limitações da abordagem de pesquisa que será ponderada a seguir.

\subsection{Limitações da abordagem de pesquisa}

O objeto desta fenomenografia é a experiência humana sobre as rotinas organizacionais durante o período de isolamento social imposto pela pandemia da Covid-19.

Note-se que o foco de análise não é aprender sobre o fenômeno, o que seria objeto da fenomenologia (MARTON, 1981). Tampouco é compreender o comportamento humano (MARTON e BOOTH, 1997). Aqui, o que verdadeiramente é objeto de pesquisa é experienciação do fenômeno pelos sujeitos que participaram da pesquisa.

Importante, neste ponto, fazer a ressalva de que a pesquisadora também experienciou o fenômeno tal qual os entrevistados e, justamente com o objetivo de manter seu distanciamento pessoal para a construção do espaço de resultados, é que despersonificou os sujeitos e ateve-se a todo o momento à técnica do método fenomenográfico o que, inclusive, proporcionou a possibilidade de identificar a existência de um coletivo de entrevistas que atendiam à finalidade da pesquisa, ao passo que outro grupo tornou-se imprestável a tal fim, como já pontuado na seção anterior. 
No entanto, nunca é demais ressaltar que a pesquisa qualitativa em uma epistemologia interpretativista é, na essência, construtivista e, por isso, parte da premissa de que a realidade é a exteriorização da prática humana e de sua interação com o mundo (SACCOL, 2009), sendo incontroverso que o pesquisador também participa desta construção (WALSHAM, 1993).

Dessa forma, não é possível falar em completa isenção da pesquisadora no desenvolvimento deste trabalho, vez que, ao menos na eleição do tema, o principal motivador foi seu interesse pessoal, tal qual destacado na seção sobre a relevância do estudo.

O método, portanto, não se apresenta como absolutamente isento de vieses, contudo por meio de uma pergunta central abrangente e não direcionada, permite que a fala do entrevistado seja capturada sem interferência do pesquisador e, considerando que o campo de análise é justamente a transcrição das entrevistas, visa resguardar o máximo de afastamento possível entre pesquisador e espaço de resultados.

Por fim, importante ressaltar que o método não se presta a julgar as pessoas ou suas experiências, mas apenas e tão somente investigar a experiência humana sobre dado fenômeno (MARTON, 1981), o qual, neste trabalho, são as rotinas organizacionais insertas no contexto de isolamento social imposto pela pandemia da COVID-19. Os resultados fruto da pesquisa serão apresentados e detalhados a seguir. 


\section{Resultados encontrados}

Neste capítulo serão expostos os resultados da pesquisa, representados pelas categorias descritivas e dimensões explicativas. Conforme se verificará a seguir, as categorias serão apresentadas a partir da menor complexidade para a maior, em um movimento de interação entre elas, ou seja, a categoria imediatamente seguinte abarca o conjunto de significados da categoria anterior e assim subsequentemente. Cada categoria será suportada pela literatura pertinente e ilustrada por trechos das entrevistas que as representam, desaguando no espaço de resultados. Esclarece-se, por oportuno, que alguns termos são específicos das rotinas organizacionais e do contexto pandêmico em que a pesquisa foi realizada, os quais constam listados no Apêndice IV e, por serem de conhecimento desta pesquisadora, não prejudicaram as análises e conclusões relacionadas. Por fim, informa-se que, antes de adentrar nas categorias descritivas e dimensões explicativas, a pesquisadora optou por fazer uma digressão sobre o trabalho remoto que se apresentou como uma condição para a consecução das rotinas organizações durante o período pandêmico para os profissionais que participaram da pesquisa.

\subsection{0 trabalho remoto e sua necessidade em razão da pandemia}

Posicionada como um desafio mundial de saúde pública sem precedentes (OMS, 2020), a pandemia da Covid-19 transformou de maneira drástica o cotidiano ao pressionar por medidas restritivas à circulação das pessoas (OMS, 2020). Nesse contexto, as empresas que não prestavam serviços essenciais instituíram o regime de trabalho remoto e, as empresas que prestavam serviços essenciais mantiveram fisicamente apenas os profissionais diretamente relacionados à atividade fim, autorizando o trabalho remoto para as atividades complementares.

O trabalho remoto abarca todo tipo de atividade laboral na qual o empregado preste seus serviços espacialmente separado do empregador, e que não configure trabalho externo, sendo o teletrabalho e o trabalho em domicílio (home officie) subespécies do trabalho remoto (MIZIARA et al.; 2020). Enquanto o teletrabalho exige a intermediação por tecnologias da informação (BRASIL,1943), o trabalho em domicílio, como o nome já revela, será aquele somente prestado na residência do empregado (MIZIARA et al.; 2020). Já o trabalho externo, que não configura 
tramalho remoto, ocorre quando a ampla maioria das atividades são realizadas externamente (BRASIL,1943), pois há necessidade, por exemplo, de realizar visitas a clientes ou conduzir outros trabalhadores da empresa para locais predeterminados.

Embora o teletrabalho já tivesse sido reconhecido pelo TST desde 2004 (TST, 2004) e positivado detalhadamente pela CLT desde 2017 (BRASIL, 2017), somente com a eclosão da pandemia é que se viu, no Brasil, um exponencial aumento do número de profissionais neste regime de trabalho (GOES et al.; 2020).

Teletrabalho, em conformidade com o artigo 75-A da CLT (BRASIL,1943), é toda "a prestação de serviços preponderantemente fora das dependências do empregador, com a utilização de tecnologias de informação" e que não configure trabalho externo.

Rodrigues (2017) ressalta que uma das desvantagens do teletrabalho seria a imposição do distanciamento social entre os colaboradores. No entanto, o que à época do referido estudo era encarado como risco para muitas empresas, com a pandemia, passou a ser a principal forma de garantir a saúde de seus colaboradores e a manutenção das atividades em contexto pandêmico (OMS, 2020).

A necessidade de isolamento social elevou o teletrabalho ao status de protagonista nas relações laborais e, dado o lapso temporal concedido para que as empresas não prestadoras de serviços essenciais encerrassem suas atividades presenciais (ESTADO DO RIO DE JANEIRO, 2020), embora as atividades laborais pudessem ser desempenhadas de qualquer lugar, no caso dos entrevistados, ficaram restritas ao ambiente doméstico (home officie).

A transposição do contrato de trabalho presencial para o contrato de trabalho remoto (teletrabalho) trouxe mudanças também na esfera financeira dos profissionais. Enquanto na modalidade presencial o empregador deveria garantir o controle de jornada (ponto por exemplo) e deveria efetuar o pagamento de horas extras; no teletrabalho o controle e o pagamento de horas extras são, em regra, dispensados (BRASIL,1943).

Da análise das 20 entrevistas selecionadas, observou-se que os profissionais deixaram de desempenhar suas atividades laborais no local específico para tanto (endereço comercial) e passaram a desempenhá-las em suas próprias casas. O mesmo aconteceu com seus companheiros e filhos, pois as crianças também tiveram que deixar de frequentar as escolas e passaram a ter aulas por salas virtuais (homeschooling). 
Em linhas gerais, a pesquisa sugeriu que os artefatos tecnológicos se mostraram indispensáveis para garantir a própria existência das rotinas organizacionais, alcançando status de centralidade e impulsionando o desenvolvimento de novas habilidades pelos atores relacionados e, em alguns casos, operou um aumento do controle das rotinas organizacionais se comparado com o período em que o trabalho era desempenhado presencialmente.

A pesquisa também sugeriu que houve uma (re)organização da dimensão tempo-espaço para garantir a produtividade dos profissionais, o que se explica pela inexigibilidade de padrão preestabelecidos para a realização das entregas; pela inclusão de novos marcos para (re)organizar a dimensão tempo-espaço e pela observação de que houve um incremento nas entregas e uma preocupação por parte das empresas com o bem-estar de seus funcionários.

Por fim, também emergiu da pesquisa uma maior capacidade de inovação com o objetivo de estabelecer novos parâmetros para manter o funcionamento da empresa para além do período pandêmico, pela interpretação conferida aos artefatos, pelo desenvolvimento de comportamento empreendedor pelos funcionários e pela repactuação das bases contratuais, além de aceleração do processo decisório.

Feita esta breve contextualização, segue-se para um maior detalhamento das categorias descritivas e respectivas dimensões explicativas.

\subsection{As categorias descritivas e as dimensões explicativas}

O presente estudo buscou investigar como se deu a experienciação das rotinas organizacionais durante o período de isolamento social imposto pela pandemia da Covid-19. Feita a coleta, tratamento e análise dos dados, o que culminou com a necessidade de exclusão de 10 das entrevistas realizadas (todas as entrevistas do grupo 2) conforme já apontado na seção de tratamento e análise dos dados, a pesquisadora identificou três categorias descritivas: i) A preservação das rotinas; ii) A (re)organização da dimensão tempo-espaço e iii) A capacidade de inovação. As categorias foram organizadas de forma que houvesse uma evolução entre elas, ou seja, a primeira categoria está contida na categoria seguinte, e assim sucessivamente. A figura 6 ilustra a disposição das categorias descritivas. 


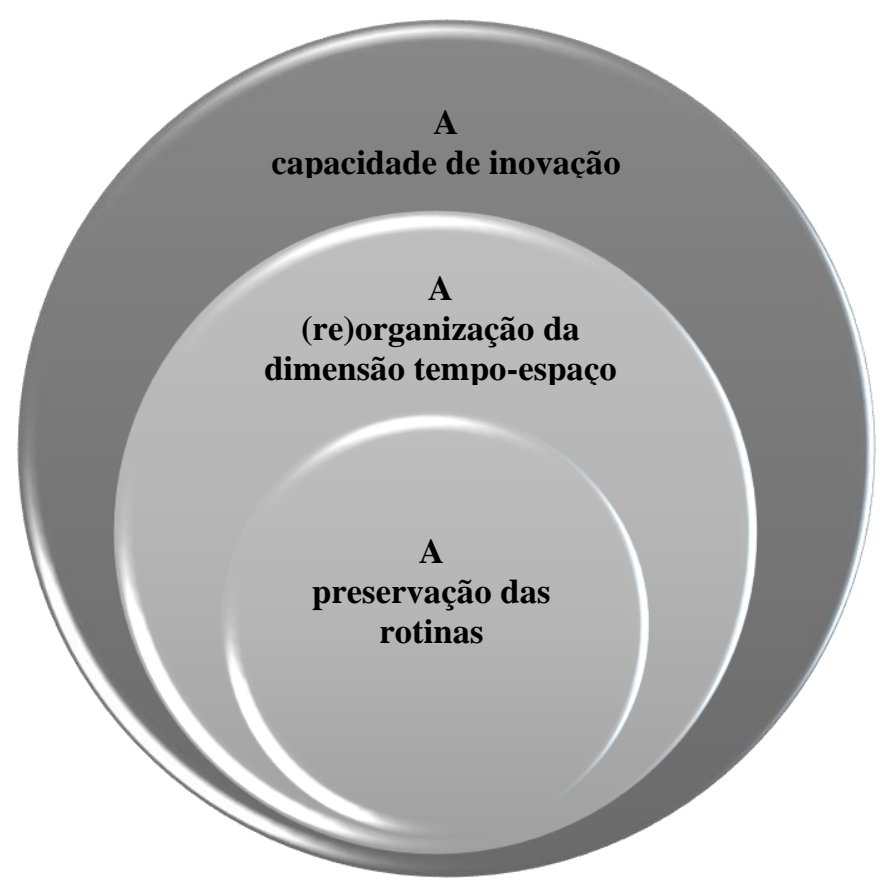

Figura 6: Organização hierárquica das categorias descritivas

Fonte: Elaborado pela autora

Cada uma das categorias possui um princípio subjacente. Conforme Mello (2000), princípios são os mandamentos nucleares de um sistema, ou seja, são o alicerce, a base de sua existência. Partindo dessa premissa, a existência das categorias é pautada em um objetivo implícito que será o norteador interpretativo de tal categoria frente as dimensões explicativas. A figura 7 relaciona as categorias descritivas e seus respectivos princípios subjacentes.

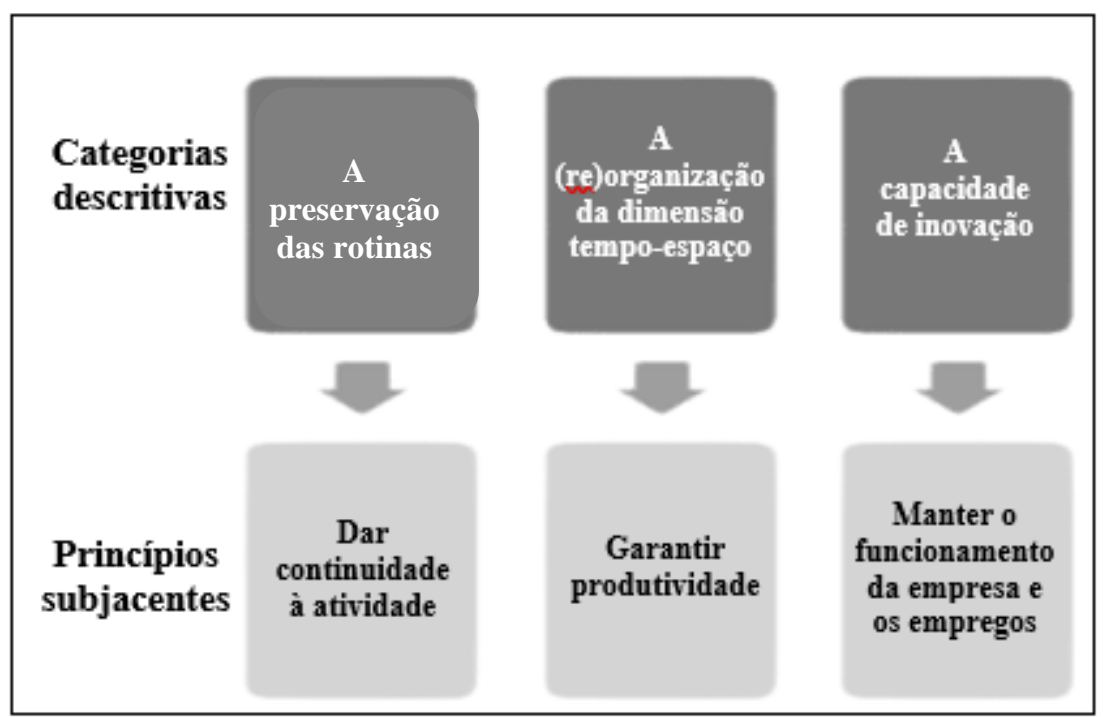

Figura 7: Correlação entre categorias descritivas e princípios subjacentes Fonte: Elaborado pela autora 
Para que uma categoria de menor complexidade esteja contida em uma categoria de maior complexidade, necessariamente as categorias precisam concomitantemente ter pontos em comum e pontos de transbordamento, e para explicá-los, a pesquisadora se valeu de quatro dimensões explicativas: i) dinamismo nos componentes operativos das rotinas; ii) aspectos técnico-comportamentais dos atores envolvidos; iii) aspectos gerenciais sobre as rotinas e iv percepção de segurança.

O dinamismo interno das rotinas organizacionais é reconhecido pela capacidade endógena para mudanças que as rotinas organizacionais possuem (FELDMAN et al.; 2016; FELDMAN \& PENTLAND, 2003). Feldman (2000) destacou a existência de dualidade entre estabilidade e mudança nas rotinas organizacionais, de forma que existe uma relação recursiva entre seus aspectos ostensivo e performativo (FELDMAN \& PENTLAND, 2003) e entre os artefatos (D’ADDERIO, 2011).

Os aspectos técnico-comportamentais dos atores envolvidos nas rotinas foram percebidos na pesquisa por meio do desenvolvimento de hard skills e soft skills e também por ações individuais e coletivas visando equilibrar o estado emocional dos atores, emergindo a percepção de que seu equilíbrio era fundamental para o cumprimento das rotinas organizacionais (BALDESSARELLI, 2018; BANKS, POLLACK \& SEERS, 2016).

Quanto aos aspectos gerenciais sobre as rotinas, notou-se uma preocupação com os pressupostos para a eficácia gerencial: (1) emprego racional do tempo; (2) foco em contribuições ou resultados; (3) obtenção de resultados com base em forças interativas; (4) concentração em áreas críticas; e (5) tomada de decisões eficaz (DRUCKER, 1974).

A correlação entre as categorias e as dimensões explicativas aponta uma evolução de uma percepção de simplesmente manter os padrões preexistentes para uma oportunidade de inovação e consequentemente diferenciação, conforme será detalhado nas sessões seguintes.

\subsubsection{A preservação das rotinas}

Com base nas entrevistas realizadas para identificar como se deu a experienciação das rotinas organizacionais durante o período de isolamento social 
imposto pela pandemia da Covid-19, a primeira categoria descritiva identificada foi “a preservação das rotinas”, cujo princípio subjacente é manter os padrões previamente existentes, ou seja, manter as rotinas organizacionais e as entregas o mais próximo possível do formato que se praticava antes da determinação de isolamento social.

Os atores relataram que suas rotinas organizacionais foram praticamente inalteradas, salvo pela inclusão de artefatos tecnológicos:

"o que eu vinha fazendo antes praticamente continuou tudo (...) as mudanças é porque a gente precisou se adaptar a essas ferramentas, então, o que antes a gente fazia via presencial, a gente já vem fazendo por vídeo." "No escritório a gente passou a utilizar mais o Zoom." (Entrevista 1)

“Na verdade, não mudou muita coisa não, foi mais parcial. Eu continuei trabalhando, assim, normal." (Entrevista 13)

Dos relatos, pode-se verificar que os artefatos tecnológicos foram os principais mediadores do trabalho (MANSELL et al,; 2007), independentemente da área de atuação (foram entrevistados profissionais de diversos setores da economia) e, especialmente em razão do contexto de isolamento social, tornou-se essencial para a execução do trabalho.

Os artefatos tecnológicos podem ser definidos como aplicações de TI estruturadas e voltadas para a realização dos processos de negócios (LEONARDI, 2011) e podem se aplicar a TI, SI e para a interação entre pessoas (LEONARDI, 2007), o que se confirmou pelos relatos dos entrevistados:

"Meus amigos do trabalho, eu falo quase todo dia por videochamada, a gente se chama assim... como se eu fosse na mesa do amigo, eu vou lá e chamo ele por vídeo, sabe? Como se eu tivesse do lado em algum café, alguma coisa assim. Então, a gente tá criando esse hábito também de se ver mais por vídeo assim." (Entrevista 8)

Segundo à dimensão explicativa relacionada ao dinamismo dos componentes operativos das rotinas, observa-se que nesta categoria houve uma maior convergência entre o aspecto ostensivo e o aspecto performativo das rotinas organizacionais, o que traz a sensação de que o aspecto ostensivo prepondera. $\mathrm{O}$ aspecto ostensivo funciona nesta categoria descritiva como um guia para o 
desempenho das rotinas (PENTLAND e FELDMAN, 2005), o qual os entrevistados desejavam manter.

“pra mim, em termos de rotina, de operacional, não mudou muito (...) então eu continuo desenvolvendo dentro da minha casa, as atividades de uma forma praticamente igual (...) Eu cumpro as atividades operacionais sozinha, sem precisar desenvolver isso com ninguém e quando eu preciso desenvolver eu tenho meios de comunicação, através de Skype." (Entrevista 3)

Os artefatos, que são elementos que fazem parte da dinâmica das rotinas organizacionais, foram interpretados pelo viés construtivista, ou seja, não possuíam propriedades objetivas em si (PINCH e BIJKER, 1987), sendo claro para os entrevistados que os artefatos não se confundiram com a própria rotina (FELDMAN e PENTLAND, 2005):

“nossa prioridade sempre foi o atendimento presencial, né, quando a gente fala de gestor, então, a gente, hoje, faz o mesmo atendimento mas online, ou telefone e e-mail." (Entrevista 15)

No que tange à dimensão explicativa relacionada aos aspectos técnicoscomportamentais dos atores envolvidos nas rotinas, nesta categoria, os entrevistados apontaram que tiveram que aprender a operar novos artefatos tecnológicos em razão do isolamento social e da necessidade do teletrabalho:

"a gente já tinha todas as ferramentas no nosso office novo [antes da pandemia], mas ninguém nunca tinha usado o Microsoft Teams, por exemplo. A gente usava o Skype ainda porque era o que a gente sabia manusear mais ou menos. A gente teve que aprender a fazer acessos de VPN (...) mas todo mundo muito ciente de que isso ia ser a nova realidade, então, a gente ia trabalhar remoto, a gente tinha que fazer a roda girar, independente da gente tá se encontrando." (Entrevista 16)

Quanto à dimensão explicativa relacionada aos aspectos gerenciais sobre as rotinas, nesta categoria, os sujeitos apontaram que a distância física entre os colaboradores acabou ensejando um aumento do monitoramento e controle por parte dos gestores:

“Os gestores, que tão lá há 20, 15 anos, tem gestores que tão lá há 30 anos, tá? E não sabiam lidar com isso. E a gente tinha reunião de status três vezes 
ao dia, tipo, uma nove da manhã, uma a uma tarde e a outra às sete da noite. Então, assim, faltava o quê? Uma confiança." (Entrevista 17)

A pesquisadora infere que esse aumento do monitoramento pode ter sido a causa para uma maior convergência entre os aspectos ostensivo e performativo das rotinas organizacionais. Inobstante a existência do movimento recursivo entre tais aspectos, os sujeitos estavam muito mais preocupados em garantir, ao menos, que a manutenção das rotinas de antes do período de isolamento. Diante disso, os artefatos tecnológicos foram utilizados apenas como viabilizadores e não propulsores da rotina, remetendo à relação recursiva ilustrada pela Figura 1.

Quanto à dimensão explicativa relacionada à percepção de segurança, a experiência de preservar as rotinas já estabelecidas no meio ambiente físico de trabalho foi o primeiro passo para garantir sensação de segurança e estabilidade aos profissionais. As falas já transcritas demonstram que, inobstante todas as mudanças provocadas pelo isolamento social imposto pela pandemia da Covid-19, os entrevistados tinham elevada percepção de segurança que a pesquisadora infere ser o produto da extrapolação das atividades correlatas aos aspectos gerenciais das rotinas.

A pesquisadora infere que o objetivo de manter o status quo ante tenha influenciado diretamente no aumento do controle exercido pelos gestores e que esta é uma categoria descritiva marcada por uma menor consciência coletiva, se comparada com a categoria seguinte de (re)organização da dimensão tempo-espaço.

\subsubsection{A (re)organização da dimensão tempo-espaço}

A experiência dos profissionais que representam a categoria descritiva de (re)organização da dimensão tempo-espaço é guiada pelo princípio subjacente de garantir a produtividade, ou seja, além de viabilizar a continuidade das rotinas organizacionais, esses profissionais conceberam, também, alcançar novos patamares de entrega.

Os atores relataram que suas rotinas foram drasticamente alteradas com a compressão do tempo e do espaço; que a divisão tempo-espaço entre as diversas tarefas desempenhadas durante o dia deixou de existir e tudo se resumiu ao tempoespaço do lar, não só para eles próprios, mas também para todos os que ali residissem. 
"no nosso caso, que temos duas filhas, os dois trabalham, e trabalho intenso, e aí a gente tenta se organizar, e até ajudar. Então, a gente acorda cedíssimo, dá café pras crianças, tem lição de casa pra fazer, e depois a gente tem que começar às nove horas o trabalho, então, a gente organiza tudo pra que isso aconteça. A gente trabalha, faz reuniões, tudo, videoconferências, o que for necessário, e onze horas eu paro pra fazer almoço, e só consigo voltar pra minha rotina mesmo duas da tarde mais ou menos. Eaí nesse meio tempo tem a aula da minha maior, aula online da minha mais nova, acaba que a gente tem que dar atenção, e normalmente umas cinco, cinco e pouco eu acabo tendo que parar porque ainda tem a casa inteira pra limpar e roupa pra lavar. Então, eu acabei tendo que me virar." (Entrevista 11)

Essa compreensão de tempo-espaço traz à baila o conceito de meio ambiente do trabalho como o conjunto de condições, existentes no local de trabalho, relativos à qualidade de vida do trabalhador (BRASIL, 1988). Dessa forma, no Brasil, garantir o equilíbrio do meio ambiente do trabalho possui status constitucional e é um dever do empregador.

Inobstante, em alguns casos os empregadores não adotaram medidas mínimas para garantir minimamente esse direito dos funcionários:

"nem todos têm acesso à internet, nem todos tem computador em casa (...) muitas das vezes não têm nem internet, só tem o celular e a internet de dados. Então, assim, não têm como acessar livremente." (Entrevista 12)

Em outros casos, no entanto, houve um esforço do empregador para garantir o mínimo de equilíbrio no ambiente de trabalho que, em razão do isolamento social, passou a ser a própria casa do funcionário:

“eles deram todo o suporte pra gente. Pra quem não tinha computador em casa, pôde levar o computador da empresa, teve gente que teve ajuda pra melhorar a internet, teve gente que pôde levar mobiliário também na empresa, eles organizaram." (Entrevista 9)

"Então, eles decretaram home office pra todo mundo. (Eles permitiram) que as pessoas buscassem cadeiras, monitores, a infraestrutura toda que quisesse levar, eles deixariam levar." (Entrevista 19)

A percepção de que o trabalho remoto reconfigurou a dimensão de tempoespaço foi fundamental para que os profissionais representantes desta categoria 
descritiva também percebessem a rotina de uma outra forma: se na primeira categoria os profissionais intentavam apenas manter a rotina que tinham antes do isolamento social; nesta categoria os profissionais reconheceram as transformações e delas se apropriaram para garantir uma maior produtividade como um motivador pessoal inclusive (RODRIGUES, 2017).

No que tange a dimensão explicativa relacionada ao dinamismo nos componentes operativos das rotinas, o que se observou foi uma maior flexibilidade quanto à forma que realização da rotina e, nesse sentido, uma possível maior divergência entre os aspectos performativo e ostensivo das rotinas organizacionais.

De acordo com Pentland e Feldman (2005), a performance está diretamente relacionada à subjetividade de cada sujeito, de forma podem ser definidas como ações específicas, praticadas por pessoas específicas, em momentos específicos, porém, relacionadas à uma rotina organizacional.

$\mathrm{O}$ aspecto performativo é inerente à prática das rotinas organizacionais e propicia a ocorrência de transformações endógenas nas rotinas. Contudo, nesta categoria descritiva observa-se que algumas empresas deixaram as rotinas um pouco mais flexíveis do que no ambiente de trabalho presencial:

"Se eu tivesse no escritório, eu não ia trabalhar no final de semana, porque é o meu momento de pessoal. Mas como durante a semana eu tô com uma rotina um pouco mais leve, então eu tô mais disponível.' (Entrevista 5)

Da análise dos relatos, a própria disponibilidade de trabalhar aos finais de semana, por exemplo (Entrevista 5) depreende-se uma maior preocupação com as entregas e com o aumento da produtividade:

“os resultados da minha equipe não caíram, muito pelo contrário. A gente tá equilibrando muito bem." (Entrevista 5)

“A gente evoluiu muito. Algumas coisas na empresa que tavam paradas, as pessoas se empolgaram mais e começaram a trabalhar com mais vontade, $e$ acabaram entregando mais rápido do que o previsto." "A gente planejava receber igual ou um pouco a menos do que as pessoas produziam na empresa, e quando as coisas foram saindo a gente ficou meio sem saber o que fazer, porque a gente... assim, a gente tinha um planejamento $X$, eles entregaram $2 X$, então, o que que a gente vai fazer com isso tudo? (Entrevista 9) 
"[a empresa], apesar dessa mudança ter sido brusca, etc., tá funcionando, e tá funcionando bem, a gente tá fazendo as coisas com mais agilidade." (Entrevista 14)

Quanto à dimensão explicativa relacionada aos aspectos técnicoscomportamentais dos atores envolvidos nas rotinas, as entrevistas demonstram a reconfiguração do espaço sociomaterial (LEONARDI, 2012) a partir da transposição do ambiente de trabalho presencial para o remoto provocou a instituição de novos sinais visuais e marcos temporais como gatilhos para agir ou decidir pelos próprios profissionais:

"Aqui em casa estamos os três no home office, né, eu, minha mulher e meu filho, que também tá estudando em casa. Então, a gente montou meio que um esquema de home office pros três ficarem no mesmo cômodo, os três ficam no quarto (...)é o ambiente onde a gente separou pra trabalhar, ele é exclusivamente pra trabalho. Assim que a gente acaba de trabalhar, a gente, obrigatoriamente, se força a sair do quarto, pra pode ter essa sensação de que, "ah pronto, acabei de trabalhar, agora vou fazer outra coisa". "Apesar de ser um home office, também não é bagunça, também não é pra trabalhar deitado na cama, de pijama. Acho que quando você faz isso, você começa a misturar a sua parte de lazer com a sua parte de trabalho." (Entrevista 9)

Ainda nesta dimensão explicativa, os profissionais desenvolveram novas competências emocionais e incluíram novas atividades em seu cotidiano:

"se afeta o meu emocional, obviamente afeta a minha rotina organizacional, de repente de eu ficar mais impaciente com determinada situação. Acho que é uma situação desse tipo, mais, assim, comportamental do que qualquer outra coisa. Respiro... Profissionalismo máster." (Entrevista 10)

Os entrevistados também apontaram uma preocupação das empresas com os funcionários, mas uma preocupação voltada para a manutenção da produtividade:

"Então, quando [a empresa] resolveu praticamente me falar que a gente ia ficar em casa até ver o que que ia acontecer, eu achei bem positivo, eu achei que foi um cuidado... parecia um zelo com os funcionários. (Entrevista 19) 
Nesse ponto, adentramos na dimensão explicativa relacionada aos aspectos gerenciais sobre as rotinas. A preocupação com o comportamento dos atores no contexto pandêmico foi elevada à abertura de agenda sobre suas condições emocionais. Ações individuais ou coletivas foram meios de equilibrar o estado emocional dos atores, emergindo a percepção de que seu equilíbrio era fundamental para o cumprimento das rotinas organizacionais (Baldessarelli, 2018; Banks, Pollack \& Seers, 2016).

Como parte do objetivo de garantir as interações sociais e contribuir para o equilíbrio emocional dos funcionários, as empresas promoveram uma maior interação entre os atores envolvidos nas rotinas:

“...o departamento que tem assim, sei lá, umas 30, 40 pessoas, o chefe fazia uma reunião quase todo dia. Coisa que no presencial não tinha, tá?" (Entrevista 14)

"Eu mantenho um chat intenso por computador, ou, no caso, às vezes por ligação com o meu chefe e com os meus outros parceiros. E a gente tem feito assim, a empresa inteira assim, com os acessos liberados, e muita comunicação, né, muito Whatsapp, muito Teams, muita ligação." (Entrevista 19)

Também visando o equilíbrio emocional (transmitir simbolicamente a sensação de segurança e cuidado) as empresas investiram na circulação da informação de forma mais horizontal:

“... a gente tem feito diversas adequações na rotina de trabalho e também uma mudança significativa na forma como a gente enxerga o contato com as outras pessoas. (...) [a empresa] adotou uma postura que é de melhoria da comunicação. (...) Então, desde o início do home office nós fazemos reuniões semanais com [a empresa] toda, todos os sócios, todas as áreas, (...) pra comentar sobre a semana, sobre as perspectivas da próxima semana, sobre as dificuldades da semana anterior, os (êxitos) da semana anterior, pra fazer uma comunicação institucional(...). Então, a equipe tá o tempo inteiro muito informada e acompanhando muito, assim, pra dar segurança mesmo, pras pessoas que trabalham com a gente, de qual o caminho que [a empresa] tá tomando nesse momento, que é um momento de tanta incerteza, né? (Entrevista 2) 
Quanto à dimensão explicativa relacionada à percepção de segurança, os relatos apresentados demonstram que, embora não tenha havido uma preocupação em manter exatamente as mesmas rotinas organizacionais que eram desenvolvidas antes do isolamento social, houve uma preocupação dos gestores em criar um espaço de segurança para que os colaboradores trabalhassem com a sensação de estarem sendo cuidados e não explorados durante um período tão delicado.

Para a criação dessa atmosfera de segurança, as empresas criaram rotinas auxiliares, não diretamente relacionadas à atividade fim empresarial, mas que os gestores concederam como fundamentais para a manutenção da atividade empresária:

"Inclusive [a empresa] começou a dar umas orientações, tipo assim, sabe?

Pras pessoas respeitarem os horários de trabalho e tal, porque essa conversa pelo Zap fica constante e ela se confunde um pouco agora com uma rotina de escritório, né?" (Entrevista 14)

Nesta categoria descritiva, a pesquisadora observou que houve uma possível maior divergência entre o aspecto performativo e o aspecto ostensivo das rotinas organizacionais. A pesquisadora infere que o princípio subjacente desta categoria tenha influenciado diretamente nessa dinâmica e também na criação de novos marcos temporais para delimitação do tempo-espaço. Com o foco na entrega, os profissionais passaram a adotar medidas que estavam ao seu alcance para viabilizar o incremento dos resultados. A postura das empresas também foi fundamental para a construção dessa categoria, uma vez que demonstraram cuidado e preocupação e tentaram construir uma atmosfera de segurança. Esta é uma categoria descritiva marcada pelo engajamento com os resultados da empresa.

\subsubsection{A capacidade de inovação}

A experiência dos profissionais que representam a categoria descritiva de capacidade de inovação é guiada pelo princípio subjacente de estabelecer novos parâmetros, ou seja, além de viabilizar a continuidade da operação, e aumentar as entregas, esses profissionais conceberam, também, transformar suas rotinas organizacionais e a própria organização. É um movimento de inovação.

Quanto ao dinamismo dos componentes operativos das rotinas organizacionais, os atores relataram que, com a determinação de isolamento social, 
se viram compelidos a deixar de lado algumas rotinas, porém, algumas dessas rotinas representavam a atividade fim da empresa:

“...com as lojas fechadas, o trabalho cessa (...) a gente não tem como vender." "o estoque, o que aconteceu foi que a gente cortou todas as compras" (Entrevista 6)

“...é muito difícil essa situação de paralisação, porque acaba gerando um prejuízo, principalmente pra quem já tem, assim, prazos... prazos também legais pra cumprir, caso de alvará, de Habite-se, então, a gente não consegue ficar muito parado, sabe?" (Entrevista 7)

Havia, portanto, uma motivação externa para mudança e a reconfiguração das formas de obtenção de recursos (FELDMAN, 2004) se fez absolutamente necessária e novas rotinas foram construídas para viabilizar o funcionamento da empresa e a manutenção dos empregos do corpo de funcionários:

"Nós tivemos que inserir diversas novas rotinas para o cuidado com a nossa tripulação. Então, a gente, além de seguir o protocolo que a Anvisa determinou, a gente incluiu outras ações de prevenção pra evitar que o vírus, de alguma forma, entre a bordo das nossas embarcações." (Entrevista 4)

"Quando isso tudo começou nós não tínhamos nenhuma atividade na venda digital da loja, tá? Nós tínhamos (parte) digital, Instagram, etc. e tal, mas não a venda sendo efetuada pelo meio digital." (Entrevista 6)

"A gente se viu numa situação onde ou demitia todos ou fazia alguma coisa" (Entrevista 7)

Conforme apontado no referencial teórico, a tecnologia tem se apresentado um importante mediador das rotinas organizacionais, independentemente da natureza da atividade (MANSELL et al.; 2007) e, nesse sentido, os artefatos tecnológicos se mostraram indispensáveis para viabilizar a continuidade da operação mediante a criação de novas rotinas-fim, ou seja, relacionadas à atividade empresarial principal:

“...todo dia a gente faz uma videoconfe... todo dia, de cinco às seis, a gente faz videoconferência com 80 pessoas. E tem sido muito saudável assim." (Entrevista 4) 
"Aí a gente passou a fazer um movimento de trabalho de venda por Whatsapp mesmo, onde basicamente a pessoa escolhia, ficava conversando o dia inteiro no Whatsapp até achar a peça escolhida, e a gente mandava por correio. (...) Anteriormente não tinha. Isso a gente que a gente implantou, né, a gente fez um WhatsApp (Business), onde a gente, basicamente, começou a anunciar na mídia social, "olha, se você quiser comprar as roupas [da empresa] você entra em contato via Whatsapp". A gente botou, claro, fez umas propagandinhas legais, etc., fez umas publicidades legais" (Entrevista 6)

Quanto aos aspectos técnicos-comportamentais dos atores envolvidos, houve uma maior necessidade do desenvolvimento de competências voltadas para a negociação entre as partes interessadas, tanto para que a organização alcançasse os resultados, quanto para que os funcionários e fornecedores ficassem apaziguados com as mudanças que estavam sendo implementadas, ensejando, algumas vezes, repactuações de bases contratuais:

“...eu tenho contado muito com a parceria do meu time e parceria dos fornecedores também. Então, a produção, hoje, de conteúdo, a produção de peças de comunicação, de arte, e, consequentemente, da aprovação delas, né, porque eu chego só na parte da aprova... eu chego na parte do planejamento e da aprovação final. Isso daí aumentou muita coisa." (Entrevista 4)

"Na minha parte foi as negociações, né, foram as negociações, é ligar pro proprietário pra negociar aluguel, ligar pra condomínio, negociar o condomínio, ligar pra Light e explicar que a minha média anual não é o que eu consumi, pra Cedae, a mesma coisa, pros fornecedores, que nós não íamos mais comprar (...) a gente negociou bastante. Agora, isso é algo curioso, porque cada negociador, cada proprietário... cada um acha uma coisa, né, e isso é interessante porque não existe uma verdade, " (Entrevista 6)

“...[a negociação com os investidores] foi um pouco complexo, porque assim, eles não queriam efetivamente que parasse, só que no momento que nós queríamos paralisar, né? Teve um que... um dos investidores, que é o majoritário em um dos projetos, ele era médico (...) no caso dele, ele pediu pra parar, ele sugeriu. (...) Foi um consenso também. Mas assim, ele teve uma visão mais pacifista sobre o assunto, e ele, em nenhum momento, quis 
tentar impor alguma coisa. Quando foi pra voltar também foi muito conversado. Então, assim, especificamente esse cara, ele foi bem tranquilo, esse investidor em específico foi tranquilo. O problema mais foi com o outro investidor, que é um cara bem mais complicado de mexer, assim, de lidar com ele é muito complexo." (Entrevista 7)

Inobstante tenha havido repactuação das bases contratuais, legalmente permitidas (BRASIL, 2020) com alguns colaboradores "cara, se você não estiver confortável de trabalhar, eu vou te suspender, você vai ficar um mês, dois meses em casa, e você volta." (Entrevista 7), nesta categoria descritiva, os aspectos gerenciais sobre as rotinas, podem ser sintetizados como o objetivo de garantir bemestar aos colaboradores.

"A gente tem um professor de educação física que dá aula de educação física pra eles todo dia de manhã. Outra coisa que a gente fez também, a gente implementou uma plataforma de saúde online, de saúde mental online, chamada Zen Club, que dá acesso também a psicólogo, coachings, psicoterapeutas. Então, a gente fez, assim, muitas ações buscando levar pra eles um bem-estar e ajudar os caras a desenvolverem alguma coisa positiva durante essa quarentena." (Entrevista 4)

“Alguns funcionários, por exemplo, quando eu disse que voltou 80\%, teve alguns funcionários que não estavam no grupo de risco e que estavam muito incomodados (...) quando envolve muito essa questão de risco, eu acho que cada um tem que saber até onde quer correr o risco ou não. Assim aconteceu, quem não trabalhou, não teve nenhuma penalidade por isso, mas assim, foi a escolha dele [funcionário] que foi respeitada." (Entrevista 7)

Ainda quanto ao aspecto gerencial, houve emprenho para promover o protagonismo dos colaboradores e houve aceleração do processo decisório:

“... o dono, né, ele tem uma armadilha muito grande na cabeça dele, que às vezes ele mesmo atrapalha a empresa. Eu acho que como agora a gente basicamente só vê os resultados, e não vê o processo acontecendo, eu me meto menos na vida dos meus funcionários e eu cobro mais resultados. Então, pra mim, foi extremamente benéfico como gestor, vamos colocar assim, tá? Porque o fato de eu ver, eu queria fazer, automaticamente eu queria me meter, tá? e não necessariamente isso melhorava a minha empresa, sabe? Eu 
acho que agora tá bem legal, porque basicamente você tá trabalhando por resultado." (Entrevista 6)

"O processo seletivo, ele é composto de várias etapas, nasce aqui comigo e termina comigo, mas antes de terminar comigo, ele dá uma volta na empresa, vai na área de segurança, vai na área técnica, vai na área de operações, vai na área de logística, de embarque e desembarque, por exemplo, e volta pra gente fazer... pra gente dar o start da admissão. Essa rotina, no presencial, era mais lenta. Agora no online, ela tá muito mais rápida. Assim, os caras tão entrevistando muito mais rápido do que entrevistavam no presencial e decidindo muito mais rápido. O que demorava, pô, às vezes duas semanas pra fechar um processo seletivo, hoje a gente fecha em três dias." (Entrevista 4)

Quanto à dimensão explicativa relacionada à percepção de segurança, a participação ativa dos colaboradores no desenvolvimento de novas rotinas-fim, ou seja, diretamente relacionadas a atividade produtiva da empresam pode ter proporcionado um sentido maior de pertencimento.

Segundo Fraser-Thill (2019), o sentimento de pertencimento pelo funcionário no local de trabalho é vital para o bem-estar, para o funcionamento organizacional e para a sensação de segurança:

"A gente entende, na minha empresa, que assim, a comunicação, hoje, ele é o fio condutor da unidade organizacional. Como as pessoas tão muito isoladas, e as pessoas, elas não estão em contato com tantas outras que nem elas estavam no presencial, a gente precisa dar um sentido de unidade aí da companhia, né, de mostrar que é uma coisa só, pro cara até poder não perder a referência do impacto do trabalho dele lá no resultado final. Então, a gente aumentou ofluxo de comunicação, a gente aumentou o número de programas e campanhas, buscando manter essa unidade organizacional." (Entrevista 4) Nesta categoria descritiva, a pesquisadora observou que houve uma maior divergência entre o aspecto performativo e o aspecto ostensivo das rotinas organizacionais se comparada com a categoria anterior, trazendo a sensação de que o aspecto performativo preponderou ao ostensivo. Além disso, a pesquisadora observou que os artefatos ocuparam um lugar de centralidade na rotina, sendo 
mediadores entre agências e, dessa forma, produzidos e reproduzidos enquanto a rotina se desenvolvia (D’ADDERIO, 2011).

A interpretação dos atores sobre o artefato viabilizou a criação de novas rotinas e não apenas a manutenção do que já era praticado no âmbito presencial. Aqui, foram criadas novas rotinas-fim (relacionadas à atividade produtiva do negócio) e também rotinas auxiliares (com foco no bem-estar e no protagonismo dos colaboradores).

O foco meramente na entrega foi substituído pelo foco em uma produtividade sustentável da empresa. Esta é uma categoria descritiva marcada por uma maior consciência coletiva.

\subsection{O espaço de resultados}

\begin{tabular}{|c|c|c|c|c|c|c|}
\hline \multirow[b]{2}{*}{$\begin{array}{l}\text { Categorias } \\
\text { descritivas }\end{array}$} & \multirow[b]{2}{*}{$\begin{array}{l}\text { Principio } \\
\text { subjacente }\end{array}$} & \multicolumn{4}{|c|}{ Dimensões explicativas } & \multirow[b]{2}{*}{ Entrevistas } \\
\hline & & $\begin{array}{c}\text { Dinamismo nos } \\
\text { componentes operativos } \\
\text { das rotinas }\end{array}$ & $\begin{array}{l}\text { Aspectos técnicos- } \\
\text { comportamentais dos } \\
\text { atores envolvidos nas } \\
\text { rotinas }\end{array}$ & $\begin{array}{l}\text { Aspectos gerenciais } \\
\text { sobre as rotinas }\end{array}$ & $\begin{array}{l}\text { Percepção de } \\
\text { segurança }\end{array}$ & \\
\hline $\begin{array}{c}\text { Preservaçã } \\
0 \text { das } \\
\text { rotinas }\end{array}$ & $\begin{array}{l}\text { Manter os } \\
\text { padrões } \\
\text { previamente } \\
\text { existentes }\end{array}$ & $\begin{array}{c}\text { Inclusão de novos } \\
\text { artefatos nas rotinas para } \\
\text { viabilizar a manutenção } \\
\text { dos padrões }\end{array}$ & $\begin{array}{l}\text { Desenvolvimento de } \\
\text { novas habilidades para } \\
\text { interagir com os novos } \\
\text { artefatos }\end{array}$ & $\begin{array}{l}\text { Foco em manter os } \\
\text { resultados que eram } \\
\text { apresentados antes do } \\
\text { isolamento social } \\
\text { Gerenciamento do tempo } \\
\text { realizado pela empresa }\end{array}$ & $\begin{array}{l}\text { Sensação de segurança } \\
\text { individual e proveninete } \\
\text { da manutenção das } \\
\text { atividades praticamente } \\
\text { inalteradas }\end{array}$ & 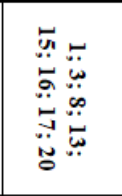 \\
\hline $\begin{array}{c}\text { A } \\
\text { (re)organiza } \\
\text { ção da } \\
\text { dimensão } \\
\text { tempo- } \\
\text { espaço }\end{array}$ & $\begin{array}{l}\text { Aumentar } \\
\text { a entrega }\end{array}$ & $\begin{array}{l}\text { Inexigibilidade de } \\
\text { configuração padrão para } \\
\text { realização das entregas }\end{array}$ & \begin{tabular}{|c} 
Necessidade de \\
estabelecer novos marcos \\
temporais para \\
delimitação de tempo- \\
espaço; Desenvolvimento \\
de habilidades técnicas
\end{tabular} & $\begin{array}{l}\text { Foco em contribuição e } \\
\text { resultados } \\
\text { Maior interação com a } \\
\text { equipe } \\
\text { Autogerenciamento do } \\
\text { tempo } \\
\text { Preocupação com os } \\
\text { funcionários }\end{array}$ & $\begin{array}{c}\text { Sensação de segurança } \\
\text { individual e proveninete } \\
\text { do aumento da entrega } \\
\text { de trabalhos para a } \\
\text { empresa. }\end{array}$ & 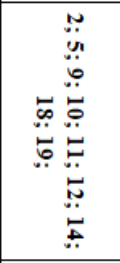 \\
\hline $\begin{array}{c}\text { A } \\
\text { capacidade } \\
\text { de inovação }\end{array}$ & $\begin{array}{l}\text { Estabelecer } \\
\quad \text { novos } \\
\text { parametros }\end{array}$ & $\begin{array}{c}\text { Inclusão de novos } \\
\text { artefatos viabilizou novas } \\
\text { rotinas }\end{array}$ & $\begin{array}{c}\text { Sentido de pertencimento } \\
\text { Negociação entre as } \\
\text { partes interessadas }\end{array}$ & $\begin{array}{c}\text { Oferecimento de } \\
\text { ferrramentas de bem } \\
\text { estar. } \\
\text { Tomada de decisões } \\
\text { eficazes } \\
\text { Aceleração do processo } \\
\text { decisório } \\
\text { Repactuação das bases } \\
\text { contratuais }\end{array}$ & $\begin{array}{l}\text { Sensação de segurança } \\
\text { coletiva e proveniente } \\
\text { da participação dos } \\
\text { colaboradores na } \\
\text { construção de novas } \\
\text { rotinas-fim, ou seja, } \\
\text { relacionadas á atividade } \\
\text { fim da empresa. }\end{array}$ & $\begin{array}{l}\stackrel{\leftrightarrow}{0} \\
\stackrel{g}{u}\end{array}$ \\
\hline
\end{tabular}

Quadro 2: Espaço de resultados

Fonte: Elaborado pela autora

\subsubsection{Interpretação sintética do espaço de resultados}

Inobstante as categorias descritivas tenham sido explicadas e ilustradas com trechos das falas dos entrevistados nas sessões 4.2.1; 4.2.2 e 4.2.3, após a demonstração gráfica do espaço de resultado, considerou-se apresentar uma síntese da leitura realizada pela pesquisadora. 
Preliminarmente, importante ressaltar que cada categoria descritiva teve o papel de representar uma espécie de fragmento da interpretação do fenômeno na ótica do coletivo de indivíduos entrevistados e, por isso, a relação entre as categorias descritivas faz emergir uma compreensão mais abrangente acerca do fenômeno (AKERLIND,2005), qual seja, rotinas organizacionais durante o isolamento social imposto pela pandemia da Covid-19. Tem-se, dessa forma, que as categorias descritivas apresentadas neste estudo não são visões isoladas do fenômeno, mas sim relacionáveis entre si.

A experiência de preservar as rotinas já estabelecidas no meio ambiente físico de trabalho foi o primeiro passo para garantir sensação de segurança e estabilidade aos profissionais. Se o mundo estava desmoronando do lado de fora e se já não era mais possível realizar as atividades cotidianas, dentre essas o ir e vir para o escritório ou empresa, era possível manter o elo com o momento em que a vida parecia em ordem por meio da manutenção das rotinas organizacionais.

A mínima interferência nas rotinas organizacionais materializadas com a inclusão de artefatos tecnológicos visando a mera transposição de espaço com relação à execução das rotinas, chegou, inclusive, a garantir a sanidade para alguns dos entrevistados que compõem esta categoria.

Não se ignora que mesmo diante da sensação de estabilidade, foi oportunizada a estes profissionais a experiências de desenvolver novas habilidades ainda que limitadas ao manuseio pleno dos novos artefatos tecnológicos, o que garantiu, de certa forma, a sensação de desenvolvimento e não de estagnação.

Contudo, para que se garantisse o funcionamento das rotinas organizacionais tal como antes do isolamento social, estes profissionais também experimentaram um crescimento do controle por parte de suas empresas, especialmente com relação ao gerenciamento do tempo. A pesquisadora não está a falar aqui de controle de jornada de trabalho, visto que, mesmo nesta categoria, os profissionais apontaram que estavam trabalhando mais horas se comparassem ao meio ambiente físico de trabalho. O que se aponta é que gerencialmente as empresas imprimiram um maior número de reuniões; e-mails, telefonemas e outros meios de contato não para fomentar a comunicação e colaboração, mas sim para se certificar de que as rotinas estavam sendo executadas sem desvios.

A experiência de (re)organizar a dimensão tempo-espaço e, consequentemente, aumentar as entregas que eram realizadas no meio ambiente 
físico de trabalho não afastou por completo a preservação das rotinas, porém conferiu aos profissionais a possibilidade de escolha entre manter o padrão ou reconfigurá-lo parcialmente, configurando-se a relação com a categoria descritiva anterior.

Se antes a sensação de estabilidade e segurança advinha apenas da manutenção das rotinas, aqui tal sensação estava amparada no aumento do volume de entregas. Há uma mudança de mindset aqui: a sensação de segurança do primeiro grupo de profissionais estava pautada no agir da empresa, na manutenção do status $q u o$; já neste grupo a sensação de segurança está fundada na capacidade de entrega individual.

O que a pesquisadora inferiu simbolicamente desta categoria descritiva é que havia orgulho dos resultados apresentados.

A experiência de inovar somente foi possível com a percepção de que era preciso manter algumas das rotinas organizacionais, estabelecendo, inclusive, um maior controle por parte da empresa em relação a estas, bem como com a percepção de que era preciso conferir autonomia para inexigibilidade de configuração padrão para algumas rotinas visando ampliar o volume de entregas. A concepção clara em diferenciar uma e outra, oportunizou uma terceira via: a da inovação.

A capacidade de inovação foi guiada pelo desejo implícito aproveitar o momento como propulsor para mudar algumas rotinas organizacionais e a própria organização, em um verdadeiro movimento de inovação.

O sentimento de orgulho pelas entregas individuais foi substituído por um maior senso de coletividade em uma via de retroalimentação entre os profissionais e a empresa. Se de um lado os profissionais se engajaram da experiência de transformar, diferenciar e perpetuar a empresa no mercado; por outro, especificamente com relação aos aspectos gerenciais, a empresa passou a olhar para esses funcionários como pessoas e preocupou-se verdadeira com o bem-estar do seu time. Quanto mais a empresa oferecia ferramentas de cuidado com o os aspectos físicos, emocionais e psicológicos de seus colaboradores, mais se dedicavam a atuar em rotinas que não eram originalmente suas, apropriando-se do resultado da empresa como se seu fosse. Não se tratava mais de uma visão solitária de barganha individualista; mais sim um pensar no todo, visando primordialmente a manutenção da empresa para além da pandemia da Covid-19. 
Essa interpretação sintética do espaço de resultados demonstra o quanto as categorias descritivas se relacionam e o quanto a dimensão explicativa relacionada aos aspectos gerenciais sobre as rotinas impactou na experienciação das rotinas organizacionais pelos profissionais, sendo indispensável tecer algumas considerações finais.

\section{Considerações finais}

Neste capítulo, serão retomados os objetivos da pesquisa, à luz dos resultados encontrados, serão apresentadas algumas conclusões complementares, limitações encontradas na pesquisa, bem como uma agenda de pesquisa, com sugestões e recomendações para futuros estudos.

Objetivo final desta pesquisa foi investigar como profissionais da cidade experienciaram suas rotinas organizacionais durante o período de isolamento social imposto pela pandemia da Covid-19.

Para viabilizar essa investigação, foram estabelecidos objetivos intermediários, dentro ao quais, revisitar as discussões acadêmicas contemporâneas acerca das rotinas organizacionais para suportar os achados da pesquisa.

Na construção do referencial teórico, foi esclarecido que, embora as rotinas organizacionais sejam objeto de análise desde o início do século passado e seu conceito tenha variado ao longo do tempo (STENE,1940; MARCH e SIMON, 1958; CYERT e MARCH, 1963; NELSON e WINTER, 1982), a pesquisadora fez a análise deste trabalho adotando como parâmetro a definição de que as rotinas organizacionais são "padrões de ações interdependentes, reconhecíveis e repetitivos" (FELDMAN e PENTLAND, 2003, p.95) e que contam com a participação de múltiplos atores (FELDMAN e PENTLAND, 2005). A partir da 
perspectiva prática das rotinas organizacionais, foi possível analisar a relação recursiva entre os aspectos ostensivo e aspecto performativo e os artefatos (FELDMAN e PENTLAND, 2005).

Especificamente quanto aos artefatos, foi feita uma incursão sobre as diversas perspectivas de conceituação (MUMFORD, 1964; WINNER, 1980; PINCH e BIJKER, 1987; CALLON E CALISKAN, 2010) e sua relação com as rotinas organizacionais como memória externa (NELSON E WINTER, 1982), como proxy da rotina (FELDMAN e PENTLAND, 2005); como elemento central da dinâmica das rotinas organizacionais (D'ADDERIO, 2011) e pela perspectiva da sociomaterialidade (SUCHMAN, 2002; LEONARDI, 2011), bem como sobre os artefatos tecnológicos (ZHANG et al;. 2011) e seu papel frente ao processo de inovação nas organizações (LEONARDI, 2011).

Para o desenvolvimento da pesquisa qualitativa, foi escolhido o método fenomenográfico tendo em vista que, em sua perspectiva de segunda ordem, busca identificar as experiências das pessoas que vivenciaram um dado fenômeno (MARTON, 1981), o que coadunava com o objetivo final deste trabalho que era compreender como os como profissionais experienciaram suas rotinas organizacionais durante o período de isolamento social imposto pela pandemia da Covid-19.

Em atenção ao método, foram selecionadas 40 pessoas para participar da pesquisa. A entrevista foi efetivamente realizada com 30 delas, havendo um lapso temporal de aproximadamente 4 meses entre o primeiro grupo de entrevistados (20 pessoas) e o segundo grupo (10 pessoas).

A análise preliminar dos relatos lançou luz para o fato de que o lapso temporal decorrido entre as entrevistas do primeiro e segundo grupos impactou diretamente na forma como os sujeitos passaram a se relacionar com o fenômeno: enquanto o primeiro grupo apresentava sua experiência sobre o fenômeno; o segundo grupo narrava o fenômeno, mantendo um distanciamento tal que os relatos transportavam a ideia de mera descrição do evento, vazia de percepções. A constatação da pesquisadora ensejou a necessidade de excluir da análise as entrevistas realizadas com o segundo grupo visto que não se prestavam ao fim pretendido por esta pesquisa.

Os resultados que emergiram das vivências dos 20 indivíduos que integraram o primeiro grupo de entrevistados resultaram na compreensão do fenômeno de três 
principais maneiras: preservação das rotinas; a (re)organização da dimensão tempoespaço e a capacidade de inovação. Essas formas de entendimento apresentaram as seguintes dimensões explicativas: dinamismo nos componentes operativos das rotinas; aspectos técnicos-comportamentais dos atores envolvidos nas rotinas e aspectos gerenciais sobre as rotinas.

A evolução das categorias descritivas em um passo mais individualista "preservar as rotinas", passando para "(re)organizar as rotinas" em um nível intermediário, até a percepção de que as rotinas insertas no contexto pandêmico eram uma oportunidade para a inovação, alçando um senso de coletividade e colaboração, caracterizara a abrangência e evolução da complexidade das categorias descritivas.

Com relação às categorias descritivas manifestadas pelos profissionais envolvidos, "preservar as rotinas" indica que os envolvidos vivenciam suas rotinas organizacionais durante o isolamento social como uma forma de manutenção de vínculo com as práticas anteriores ao isolamento social. Repetidas vezes os atores repetiram que não vislumbraram alterações em suas rotinas, que foram integralmente transpostas do ambiente físico para o virtual. Essa experiencia foi suportada também por aspectos gerenciais tendentes a aumentar o controle exercido sobre as rotinas, realizando mais reuniões, muitas vezes desnecessárias, no dizer dos entrevistados.

$\mathrm{Na}$ categoria descritiva "(re)organização da dimensão tempo-espaço, os entrevistados experienciaram suas rotinas organizacionais durante o isolamento social compreendendo a necessidade de realizar alterações para que, além de manter as rotinas, fosse possível potencializar as entregas realizadas no período. Dos relatos, a pesquisadora percebeu uma dimensão de medo dos profissionais que entendiam que, por estarem trabalhando remotamente, deveriam se dedicar mais às entregas. Inobstante tal percepção, as dimensões explicativas que suportaram esta categoria direcionaram para a inexistência de um padrão para a realização das rotinas, garantindo maior espaço para visualização do aspecto performativo. Embora tenha havido a necessidade de estabelecer novos marcos temporais e espaciais, tais delimitações foram realizadas pelos próprios profissionais, que também acabaram desenvolvendo novas habilidades, principalmente técnicas, uma vez que dedicaram tempo a aprender novas atividades. A organização, por seu turno, suportou essa experienciação com um menor controle das rotinas se 
comparado com a categoria anterior e promovendo uma maior interação entre os atores, deixando clara sua preocupação com os funcionários, especialmente com sua saúde física e laboral.

Já na categoria descritiva "capacidade de inovação", os entrevistados experienciaram suas rotinas organizacionais durante o isolamento social como meio de interromper rotinas e criar rotinas novas, o que impactou diretamente na capacidade deste grupo criar formas de captar recursos para a organização. Os novos artefatos foram integrados como viabilizadores dessas novas rotinas. Dos relatos, a pesquisadora depreendeu que as dimensões explicativas que suportaram esta categoria direcionaram para o desenvolvimento de habilidades de comunicação, especialmente relacionadas à negociação com partes interessadas. A organização adotou uma postura integrativa para estimular o senso de pertencimento dos funcionários. Além disso, ofereceu ferramentas visando garantir o bem-estar de seus colaboradores. A pesquisadora infere que a postura adotada pela organização foi preponderante para que os profissionais se tornassem mais eficazes na tomada de decisões, inclusive com aceleração desse processo, sendo clara na repactuação das bases contratuais.

Este estudo sugere, então, as dimensões explicativas sobre as rotinas organizacionais insertas no isolamento social imposto pela pandemia da Covid-19 parecem estar em linha com a definição de rotinas organizacionais que as considera como "padrões de ações interdependentes, reconhecíveis e repetitivos" (FELDMAN e PENTLAND, 2003, p.95), que contam com a participação de múltiplos atores (FELDMAN e PENTLAND, 2005) e que contribuem tanto para estabilidade, quanto para as mudanças que se visualizam dentro das organizações (PENTLAND e FELDMAN, 2005). Sugere, ainda, que a relação recursiva entre os aspectos ostensivo e performativo com os artefatos, nem sempre colocará estes últimos como centro da dinâmica das rotinas (FELDMAN e PENTLAND, 2005). Sugere, por fim, que a tecnologia é confundida com inovação (LEONARDI, 2011) e que os debates sobre artefatos tecnológicos trazem consigo para o ambiente de debate os problemas relacionados ao processo de inovação. (LEONARDI, 2011).

A pesquisadora infere que o espaço de resultados demonstrou que os aspectos gerenciais exerceram forte influência sobre a experienciação dos atores quanto às rotinas organizacionais insertas no isolamento social causado pela pandemia da Covid-19. 


\subsection{Agenda de pesquisa}

Ao longo da análise dos relatos com objetivo de responder à pergunta de como se deu a experienciação das rotinas organizacionais durante o período de isolamento social imposto pela pandemia da Covid-19, algumas provocações surgiram, contudo, como não estavam insertas na delimitação do estudo, não foi possível investigá-las.

Como sugestão, partindo dos mesmos relatos que foram utilizados para a construção do espaço de resultado desta pesquisa, seria interessante se debruçar sobre o imbricamento do território laboral e o doméstico, considerando a diversidade de gênero, para fazer uma análise comparativa entre a experiencia do fenômeno por homens e mulheres.

Também com relação aos relatos capturados em razão desta pesquisa, a necessidade de teletrabalho também impôs a necessidade de liberação de acesso livre (em qualquer hora e local) a informações antes acessadas somente em espaço controlado (rede local) e com isso emerge a relevância de analisar a rotina de proteção de dados e as rotinas de compliance durante o isolamento social.

Transbordando os relatos que constam neste trabalho, contribuiria com a compreensão mais ampla do fenômeno, cotejá-los com entrevistas realizadas com outros profissionais que, trabalhando na mesma empresa que proporcionou o teletrabalho aos entrevistados, tiveram que manter presencialmente suas atividades laborais, mesmo em contexto pandêmico, e verificar como foi essa experiência.

Para fins de acompanhar os desdobramentos desta pesquisa, propõe-se realizar uma nova entrevista com os profissionais que se mantiveram na empresa da época em que foi realizada a primeira entrevista, para averiguar se as mudanças verificadas nas rotinas organizacionais no período de isolamento social se mantiveram com a retomada do trabalho presencial.

Ainda em linha com o acompanhamento dos desdobramentos desta pesquisa, sugere-se voltar a análise para como as organizações utilizaram este momento para a construção de memória e (re)construção da identidade organizacional.

Seguir com as investigações na área de organizações e com olhos voltados para a pandemia da Covid-19 e suas externalidades sociais contribuirá 
sobremaneira para a comunidade acadêmica, dada a contemporaneidade do tema e o impacto que vem representando para as empresas e para os profissionais.

\section{Referências Bibliográficas}

AKERLIND, G. L. Variation and commonality in phenomenographic research methods. Higher Education Research \& Development. v. 24, n. 4, November, 2005, p. 321-334.

BALDESSARELLI, G. The Role of Emotions toward Artifacts in Interorganizational Routines, jul. 2018. In: Academy of Management Proceedings, n. 1, p. 12775. Briarcliff Manor, NY 10510: Academy of Management, 2018.

BANKS, G. C.; POLLACK, J. M.; SEERS, A. Team coordination and organizational routines: bottoms up-and top down. Management Decision, 2016.

BRASIL. Art. 225 da Constituição Federal de 1988. Senado Federal, Brasília, D. F. Diário Oficial da União, 1988. Disponível em: http://www.planalto.gov.br/ccivil 03/constituicao/constituicao.htm. Acesso em: 23 abr. 2021.

BRASIL. Lei no 13.467, de 13 de julho de 2020. Altera a Consolidação das Leis do Trabalho (CLT), aprovada pelo Decreto-Lei $n^{\circ} 5.452$, de $1^{\circ}=$ de maio de 1943, e as Leis $\mathrm{n} \circ 6.019$, de 3 de janeiro de 1974, 8.036, de 11 de maio de 1990, e 8.212, de 24 de julho de 1991, a fim de adequar a legislação às novas relações de trabalho. DOU, 14.07.2017. Pag. 1.

BRASIL. Lei no 13.979, de 06 de fevereiro de 2020. Dispõe sobre as medidas para enfrentamento da emergência de saúde pública de importância internacional decorrente do coronavírus responsável pelo surto de 2019. DOU, 07.02.2020. Pag. 1. 
BECKER, M. C. Organizational routines: a review of the literature. Industrial and Corporate Change, v.13, n.4, p.643-677, 2004.

BOWDEN, J.; GREEN, P. Doing developmental phenomenography. Melbourne: PMIT Publishing, 2005.

BOWDEN, J.; WALSH, E. Phenomenography. Qualitative Research Methods Series. Melbourne: MIT University Press. 2000.

CACCIATORI, E. Resolving Conflict in Problem-Solving: Systems of Artefacts in the Development of New Routines. Journal off Management Studies, p.1559 - 1585, 2012.

CAMERON, Kim S.; QUINN, Robert E. Diagnosing and changing organizational culture: Based on the competing values framework. John Wiley \& Sons, 2011.

CHERMAN, A.; ROCHA-PINTO, S. R. Fenomenografia e a valoração do conhecimento nas organizações: diálogo entre método e fenômeno. XXXIX Encampada, Belo Horizonte, 2015.

COHENDET, P. S; SIMON, L. O. Always Playable: Recombining Routines for Creative Efficiency at Ubisoft Montreal's Video Game Studio. Organization Science, 2016.

COOMBS, C. R. When planned IS/IT project benefits are not realized: a study of inhibitors and facilitators to benefits realization. International Journal of Project Management, v. 33, n. 2, p. 363-379, 2015.

CRESWELL, J. W. Projeto de pesquisa métodos qualitativo, quantitativo e misto. In: Projeto de pesquisa métodos qualitativo, quantitativo e misto. Artmed, 2010.

CYERT, Richard M. et al. A behavioral theory of the firm. Englewood Cliffs, NJ, v. 2, 1963.

D'ADDERIO, L. Configuring software, reconfiguring memories: the influence of integrated systems on the reproduction of knowledge and routines. Industrial and Corporate Change, v. 12 Iss 2, p. 321 - 350, 2003.

D'ADDERIO, L. Artifacts at the center of routines: Performing the material turn in routines theory. Journal of Evolutionary Economics, 2007.

D'ADDERIO, L. The performativity of routines: theorizing the influence of artefacts and distributed agencies on routines dynamics. Research políc., n. 37; ed. 5, 769-789 p., 2008.

D'ADDERIO, L. Artifacts at the centre of routines: performing the material turn in routines theory. Journal of Institutional Economics, v. 7 Iss 2, p. 197-230, 2011. 
D'ADDERIO, Luciana; POLLOCK, Neil. Performing modularity: Competing rules, performative struggles and the effect of organizational theories on the organization. Organization Studies, v. 35, n. 12, p. 1813-1843, 2014.

DANNER-SCHRÖDER, A.; GEIGER, D. Unravelling the motor of patterning work: Toward an understanding of the microlevel dynamics of standardization and flexibility. Organization Science, n.27. v.3, 633658, 2016.

DEKEN, F. et al. How routines afford and constrain the generation and incorporation of novelty. In: 29th European Group of Organizational Studies Colloquium. EGOS, 2013.

EBERHARD, J., FROST, A., \& RERUP, C. The dark side of routine dynamics: Deceit and the work of Romeo pimps. In: FELDMAN, M.; D'ADDERIO, L.; DITTRICH, K.; JARZABKOWSKI, P. Routine Dynamics in Action: Replication and Transformation. Research in the Sociology of Organizations, Vol. 61. Bingley: Emerald Publishing Limited, 99-121, 2019.

Eberhard, J., Frost, A., \& Rerup, C. (2019): "The dark side of routine dynamics: Deceit and the work of Romeo pimps." In: M. Feldman, L. D'Adderio, K. Dittrich \& P. Jarzabkowski (eds.): Routine Dynamics in Action: Replication and Transformation. Research in the Sociology of Organizations, Vol. 61. Bingley: Emerald Publishing Limited, 99-121.

ESTADO DO RIO DE JANEIRO. Decreto no 49.973, de 16 de março de 2020. Reconhece a situação de emergência na saúde pública do estado do Rio de Janeiro em razão do contágio e adota medidas enfrentamento da propagação decorrente do novo Coronavirus (COVID-19); e dá outras providências. DOE. IOERJ, 17.03.2020. № 49-A. Pag. 1.

FELDMAN, M. S. Organizational routines as a source of continuous change. Organization science, n.11, ed. 6; 611-629 p., 2000.

FELDMAN, M. S.; PENTLAND, B. T. Reconceptualizing organizational routines as a source of flexibility and change. Administrative science quarterly, n. 48, ed. 1; 94-118 p., 2003.

FELDMAN, M. S.; ORLIKOWSKI, W. J. Theorizing practice and practicing theory. Organization science, n. 22, ed. 5; 1240-1253 p., 2011.

FELDMAN, M. S. et al. Routines, disruption and the temporalities of continuity. Presentation, European Group of Organization Studies (EGOS), Brussels, Belgium, July, v. 5, 2013. FELDMAN, M.; WORLINE, M. The practicality of practice theory. Academy of Management Learning \& Education, n. 15, ed. 2; 304-324 p., 2016.

FRASER-THILL, R. 4 maneiras de promover o sentimento de pertencimento no trabalho. Forbes, São Paulo, 2019. [site de internet]. Disponível em: https://forbes.com.br/carreira/2019/09/4-maneiras-de- 
promover-o-sentimento-de-pertencimento-no-trabalho/Acesso em: 20 abr. 2021.

FUNDAÇÃO OSWALDO CRUZ (FIOCRUZ). Observatório Covid-19. [site de internet]. 2020. Disponível em: https://portal.fiocruz.br/observatoriocovid-19. Acesso em: 10 abr. 2021.

GEERTZ, Cliford. A interpretação das culturas. 2012.

GIDDENS, A. Action, subjectivity, and the constitution of meaning. Social Research, v.53, n.3, p.529-545. 1986.

GÓES, G. S.; MARTINS, F. S.; NASCIMENTO, J. A. S. Potencial de teletrabalho na pandemia: um retrato no Brasil e no mundo. Carta de Conjuntura, n. 47, 2o trimestre de 2020. IPEA. [site de internet]. Disponível em:

https://www.ipea.gov.br/portal/images/stories/PDFs/conjuntura/200608_nt _cc47_teletrabalho.PDF. Acesso em: 20 set. 2020.

HARTNELL, Chad A.; OU, Amy Yi; KINICKI, Angelo. Organizational culture and organizational effectiveness: a meta-analytic investigation of the competing values framework's theoretical suppositions. Journal of applied psychology, v. 96, n. 4, p. 677, 2011.

HOWARD-GRENVILLE, Jennifer A. The persistence of flexible organizational routines: The role of agency and organizational context. Organization science, v. 16, n. 6, p. 618-636, 2005.

KANT, I. Crítica da razão pura. São Paulo: Abril Cultural, 1980.

LEONARDI, P. M. Activating the informational capabilities of information technology for organizational change. Organization science, v. 18, n. 5, p. 813- 831, 2007.

LEONARDI, P. M. When flexible routines meet flexible technologies: Affordance, constraint, and the imbrication of human and material agencies. MIS quarterly, 147-167 p., 2011.

LEONARDI, P. M. Materiality, Sociomateriality, and Socio-Technical Systems: What Do These Terms Mean? How Are They Related? Do We Need Them? In: LEONARDI, P. M.; NARDI, B. A.; KALLINIKOS, J. (ed.). Materiality and Organizing: Social Interaction in a Technological World. Oxford: Oxford University Press, p.25-48, 2012.

MANSELL, R.; AVGEROU, C.; QUAD, D.; SILVERSTONE, R. The Oxford Handbook of Information and Communication Technologies, Oxford, 2007.

MARCH, James G.; SIMON, Herbert A. Organizations. 1958.

MARCH, James G.; BOOTH, Shirley A. Learning and awareness. Psychology Press, 1997. 
MARTON, F. Phenomenograpy: describing conceptions of the world around us. Instructional Science. n. 10, p. 177-200. Amsterdam, 1981.

MARTON, F. Phenomenography: a research approach to investigating different understandings of reality. In: SHERMAN, R.; WEBB, R. Qualitative research in Education: focus and methods. London: Falmer Press, 1986.

MELLO, Celso Antônio Bandeira de, Curso de Direito Administrativo. 12 ed. - São Paulo: Malheiros, 2000, p. 747/748.

MIZIARA, F.C.R; JUNIOR,A.U.S; GASPAR, D.G. Direito do trabalho de emergência: impactos da COVID-19 no direito do trabalho. São Paulo: Thomson Reuters Brasil, 2020. Pág. 68-69.

NELSON, Richard R.; WINTER, Sidney G. An evolutionary theory of economic change. Harvard University Press, 1982.

ORLIKOWSKI, W. J. Sociomaterial practices: exploring technology at work. Organization studies, n. 28, ed. 9, 1435-1448 p., 2007.

ORLIKOWSKI, W. J.; BAROUDI, J. Studying information technology in organizations: research approaches and assumptions. Information Systems Research, v. 2, n. 1, p. 1-28, 1991.

PARMIGIANI, A.; HOWARD-GRENVILLE, J. Routines revisited: Exploring the capabilities and practice perspectives. Academy of Management Annals, v. 5, n. 1, p. 413-453, 2011.

PENTLAND, B. T.; FELDMAN, M. S. Organizational routines as a unit of analysis. Industrial and corporate change, n. 14, ed. 5, 793-815 p., 2005.

RODRIGUES, Deusmar José. et al. Lei da Reforma Trabalhista Comentada Artigo por Artigo. Leme: JH Mizuno, 2017

SACCOL, A. Z. Um retorno ao básico: compreendendo os paradigmas de pesquisa e sua aplicação na pesquisa em Administração. Rev. Adm. UFSM, Santa Maria, v. 2, n. 2, p. 250-269, maio/ago. 2009.

SANDBERG, J. Are phenomenographic results reliable? Nordisk Pedagogic. v. 15. 1995.

SANDBERG, J. Understanding human competence at work: an interpretative approach. Academy of management journal, v. 43, n. 1, p. 9-25, 2000.

SANTOS, L. S.; LEAL, F. G.; ALPERSTEDT, G. D.; FEUERSCHUTTE, S. G. O método fenomenográfico na pesquisa científica em Administração no Brasil: análise e discussão sobre seu uso. Revista de Ciências da Administração, v. 20, n. 50, p. 129-146, abril. 2018. 
Suchman, L., Trigg, R., \& Blomberg, J. Working artefacts: ethnomethods of the prototype. The British journal of sociology, v.53, n.2, p.163-179, 2002.

SIN, S. Considerations of quality of phenomenographic research. International Journal of Qualitative Methods, v. 9, n. 4, p. 305-320, 2010.

STENE, Edwin O. An Approach to a Science of Administration. American Political Science Review, v. 34, n. 06, p. 1124-1137, 1940.

TIGHT, M. Phenomenography: the development and application of an innovative research design in higher education research. International Journal of Social Research Methodology, v. 19, n. 3, p. 319-338, 2016.

Tribunal Superior do Trabalho (TST). Agravo de Instrumento em Recurso de Revista. Ministro Relator: Renato de Lacerda Paiva, n. 81223502.2001.5.01.5555, DJ: [site de internet], 13 out. 2004. Disponível em: https://jurisprudencia.tst.jus.br/\#630a6cf9505b61fbe1a9a301410ebef4.

Acesso em: 20 ago. 2020.

TURNER, S.; RINDOVA, V. P. Watching the clock: Action timing, patterning, and routine performance. Academy of Management Journal, n. 61, v. 4, 1253-1280, 2018.

VALLS, A.L.M. Ética na contemporaneidade. In: Seminário Aids quo vadis: tendências e perspectivas da epidemia no Rio Grande do Sul, 1997, Porto Alegre. Universidade Federal do Rio Grande do Sul, 1997. [site de internet] Disponível em: https://www.ufrgs.br/bioetica/eticacon.htm. Acesso em: 20 abr. 2021.

VERGARA, S. C. et al. Paradigma interpretacionista: a busca da superação do objetivismo funcionalista nos anos 1980 e 1990. Revista de Administração de Empresas, v. 45, n. 4, p. 66-72, 2005.

VERGARA, S. C; VIEIRA, M.M.F. Sobre a dimensão tempo-espaço na análise organizacional. Revista de Administração Contemporânea, v. 9, n. 2, p. $103-119,2005$.

VICK, T. E.; MACHADO, D. D. P.; PAIVA JUNIOR, F. G.; CASTRO, C. C. Desafios organizacionais do Século XXI: uma introdução ao fórum sobre inovação, capacidades dinâmicas, capacidade de absorção do conhecimento e relações simbólicas. RAM, REV. ADM. MACKENZIE, $n$. 16, v. 3, Ed. Especial, p. 14-19. São Paulo, SP. mai/jun, 2015.

VIEIRA, P. Poder e Alta Performance: o manual prático para reprogramar seus hábitos e promover mudanças profundas em sua vida. São Paulo. Gente, 2017.

WALSHAM, G. Interpreting information systems in organizations. West Sussex: John Wiley\&Sons, 257 p., 1993. 
WORLD HEALTH ORGANIZATION (OMS). Considerations in adjusting public health and social measures in the context of COVID-19: interim guidance, $16 \quad$ apr. $2020 . \quad$ Disponível em: https://www.who.int/publications/i/item/considerations-in-adjusting-publichealth-and-social-measures-in-the-context-of-covid-19-interim-guidance. Acesso em: 28 fev. 2021.

ZHANG, P.; SCIALDONE, M.; KU, M. C. IT artifacts and the state of IS research. In: Proceedings of the International Conference on Information Systems. Shanghai, China, December 04 - 07, 2011.

ZOLLO, M.; WINTER, S. G. Deliberate learning and the evolution of dynamic capabilities. Organization Science, v.13, n.3, p.339-351, 2002. 


\section{Apêndice I - Roteiro Semiestruturado}

\section{Apresentação:}

Inicialmente agradeço por sua disponibilidade em participar desse processo de pesquisa. Em segundo lugar, preciso de sua autorização para gravar essa entrevista.

Ressalto que esse conteúdo será utilizado apenas para fins acadêmicos, resguardado seu anonimato. Você me autoriza? Apenas para lhe deixar confortável com a conversa que irá se seguir, ressalto que todas as informações que foram trazidas ao longo de nosso diálogo serão utilizadas estritamente para fins acadêmicos, preservada a fonte.

Por último, mas não menos importante, vou lhe explicar como se dará a nossa conversa: incialmente farei perguntas preliminares para sua contextualização profissional. Após, farei uma breve contextualização sobre a pergunta central da pesquisa e, então, iniciaremos nossa conversação.

\section{Perguntas introdutórias:}

1. Qual é o seu gênero?

2. Qual é a sua idade?

3. Quanto tempo você tem de experiência profissional?

4. Atualmente, você está trabalhando?

5. Se sim, em qual segmento?

6. A empresa em que você trabalha é de pequeno, médio ou grande porte?

7. Há quanto tempo você está nessa empresa?

8. Qual é o seu cargo nessa empresa e qual é a atividade que você desenvolve?

\section{Breve contextualização antes da pergunta central}

Finda a nossa parte introdutória, é importante que eu ressalte as diversas informações que recebemos diariamente sobre o contexto pandêmico que vem assolando o Brasil e o mundo. A doença COVID-19, causada pelo novo Coronavirus, foi reconhecida pela Organização Mundial de Saúde como uma pandemia e muito em razão de ainda não haver um medicamento eficaz para seu combate, os Governos adotaram medidas de isolamento social para mitigar, desacelerar e retardar o contágio das pessoas por esta enfermidade. 


\section{Pergunta central}

Dado o contexto pandêmico e o contexto de isolamento social, eu gostaria que você me contasse como você tem experienciado suas rotinas organizacionais.

\section{Perguntas acessórias}

1. Você poderia me dar um exemplo?

2. Você poderia me explicar (isso) melhor?

3. Como você faz/fez (isso)?

4. Por que (isso) ocorreu?

5. Como você superou (isso)?

6. Como (isso) te ajudou?

7. Para quem?

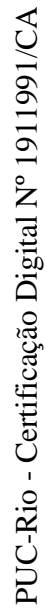

8. Por quê? 


\section{Apêndice II - Detalhamento dos sujeitos entrevistados no}

\section{período de 14 de junho de 2020 a 21 de junho de 2020}

\begin{tabular}{|c|c|c|c|c|c|c|c|c|}
\hline \multicolumn{9}{|c|}{ GRUPO 1} \\
\hline & Gênero & Idade & $\begin{array}{c}\text { Tempo de } \\
\text { Experiência } \\
\text { Profissional } \\
\text { (em anos) }\end{array}$ & $\begin{array}{c}\text { Tempo de } \\
\text { Trabalho na } \\
\text { Empresa } \\
\text { Atual } \\
\text { (em anos) }\end{array}$ & $\begin{array}{l}\text { Segmento da } \\
\text { Empresa Atual }\end{array}$ & $\begin{array}{c}\text { Porte da } \\
\text { Empresa } \\
\text { Atual }\end{array}$ & Cargo Atual & $\begin{array}{c}\text { Função } \\
\text { Atual }\end{array}$ \\
\hline 1 & Feminino & 31 & 8 & $\begin{array}{c}02 \text { anos e } 04 \\
\text { meses }\end{array}$ & $\begin{array}{l}\text { Consultoria } \\
\text { Jurídica }\end{array}$ & $\begin{array}{l}\text { Grande } \\
\text { porte }\end{array}$ & Analista de RH & Operacional \\
\hline 2 & Feminino & 35 & 10 & 10 meses & $\begin{array}{l}\text { Consultoria } \\
\text { Jurídica }\end{array}$ & $\begin{array}{l}\text { Pequeno } \\
\text { porte }\end{array}$ & Sócia & Gerencial \\
\hline 3 & Feminino & 38 & 12 & 03 anos & $\begin{array}{l}\text { Consultoria } \\
\text { Jurídica }\end{array}$ & $\begin{array}{l}\text { Médio } \\
\text { porte }\end{array}$ & Advogada & Operacional \\
\hline 4 & Masculino & 39 & 24 & $\begin{array}{c}06 \text { anos e } 06 \\
\text { meses }\end{array}$ & $\begin{array}{l}\text { Cabotagem } \\
\text { Industrial }\end{array}$ & $\begin{array}{l}\text { Grande } \\
\text { porte }\end{array}$ & Gerente de RH & Gerencial \\
\hline 5 & Feminino & 30 & 12 & 06 anos & $\begin{array}{c}\text { Industria } \\
\text { Automotiva }\end{array}$ & $\begin{array}{c}\text { Grande } \\
\text { porte }\end{array}$ & $\begin{array}{c}\text { Gerente de } \\
\text { Planejamento }\end{array}$ & Gerencial \\
\hline${ }^{\prime}$ & Masculino & 29 & 9 & 09 anos & Varejo de roupas & $\begin{array}{l}\text { Pequeno } \\
\text { porte }\end{array}$ & $\begin{array}{c}\text { Sócio } \\
\text { Administrador }\end{array}$ & Gerencial \\
\hline - & Masculino & 29 & 12 & 12 anos & Construção Civil & $\begin{array}{l}\text { Pequeno } \\
\text { Porte }\end{array}$ & Sócio & Gerencial \\
\hline 童 & Feminino & 35 & 13 & 07 anos & Judiciário & $\begin{array}{l}\text { Grande } \\
\text { Porte }\end{array}$ & $\begin{array}{c}\text { Técnica } \\
\text { Judiciária }\end{array}$ & Operacional \\
\hline 要 & Masculino & 36 & 20 & 04 anos & Editora & $\begin{array}{l}\text { Grande } \\
\text { porte }\end{array}$ & Webdisegner & $\begin{array}{c}\text { Operacional/ } \\
\text { Gerencial }\end{array}$ \\
\hline 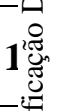 & Masculino & 33 & 17 & 06 anos & Telecomunicações & $\begin{array}{l}\text { Grande } \\
\text { porte }\end{array}$ & $\begin{array}{l}\text { Tecnical Project } \\
\text { Manager }\end{array}$ & Gerencial \\
\hline 1 & Feminino & 40 & 21 & $\begin{array}{c}02 \text { anos e } 06 \\
\text { meses }\end{array}$ & $\begin{array}{l}\text { Consultoria } \\
\text { Jurídica }\end{array}$ & $\begin{array}{l}\text { Médio } \\
\text { porte }\end{array}$ & $\begin{array}{l}\text { Consultora de } \\
\text { Negócios }\end{array}$ & Comercial \\
\hline 1 & Feminino & 31 & 6 & 06 anos & Educação & $\begin{array}{l}\text { Grande } \\
\text { porte }\end{array}$ & Professora & Operacional \\
\hline 13 & Masculino & 36 & 17 & 06 anos & $\begin{array}{l}\text { Atacado material } \\
\text { de construção }\end{array}$ & $\begin{array}{l}\text { Pequeno } \\
\text { porte }\end{array}$ & $\begin{array}{c}\text { Supervisor } \\
\text { Administrativo }\end{array}$ & Operacional \\
\hline 14 & Feminino & 57 & 35 & 27 anos & $\begin{array}{l}\text { Banco de } \\
\text { Fomento } \\
\end{array}$ & $\begin{array}{l}\text { Grande } \\
\text { porte }\end{array}$ & Técnica & Operacional \\
\hline 15 & Feminino & 36 & 15 & $\begin{array}{c}05 \text { anos e } 06 \\
\text { meses }\end{array}$ & Saúde & $\begin{array}{l}\text { Grande } \\
\text { porte }\end{array}$ & $\begin{array}{l}\text { Cordenadora de } \\
\text { Relacionamento }\end{array}$ & Gerencial \\
\hline 16 & Feminino & 33 & 13 & $\begin{array}{c}02 \text { anos e } 06 \\
\text { meses }\end{array}$ & Televisão & $\begin{array}{l}\text { Grande } \\
\text { porte }\end{array}$ & $\begin{array}{c}\text { Analista de } \\
\text { Planejamento } \\
\text { Sênior }\end{array}$ & Operacional \\
\hline 17 & Feminino & 34 & 16 & 01 ano & Energia & $\begin{array}{l}\text { Grande } \\
\text { porte }\end{array}$ & Product Onwer & Gerencial \\
\hline 18 & Masculino & 52 & 35 & 04 anos & Informática & $\begin{array}{l}\text { Pequeno } \\
\text { porte }\end{array}$ & Sócio & $\begin{array}{l}\text { Gerencial/ } \\
\text { Comercial }\end{array}$ \\
\hline 19 & Masculino & 30 & 6 & 04 meses & $\begin{array}{l}\text { Mercado } \\
\text { Financeiro }\end{array}$ & $\begin{array}{l}\text { Pequeno } \\
\text { porte }\end{array}$ & Analista de Risco & Operacional \\
\hline 20 & Feminino & 34 & 14 & 05 anos & Construção Civil & $\begin{array}{l}\text { Pequeno } \\
\text { porte }\end{array}$ & $\begin{array}{c}\text { Analista } \\
\text { Financeiro }\end{array}$ & Operacional \\
\hline
\end{tabular}




\section{Apêndice III - Detalhamento dos sujeitos entrevistados no período de 19 de outubro de 2020 a 23 de outubro de 2020}

\begin{tabular}{|c|c|c|c|c|c|c|c|c|}
\hline \multicolumn{9}{|c|}{ GRUPO 2} \\
\hline & Gênero & Idade & $\begin{array}{l}\text { Tempo de } \\
\text { Experiência } \\
\text { Profissional } \\
\text { (em anos) }\end{array}$ & $\begin{array}{c}\text { Tempo de } \\
\text { Trabalho } \\
\text { na } \\
\text { Empresa } \\
\text { Atual } \\
\text { (em anos) } \\
\end{array}$ & $\begin{array}{c}\text { Segmento da } \\
\text { Empresa } \\
\text { Atual }\end{array}$ & $\begin{array}{c}\text { Porte da } \\
\text { Empresa } \\
\text { Atual }\end{array}$ & Cargo Atual & $\begin{array}{c}\text { Função } \\
\text { Atual }\end{array}$ \\
\hline 1 & Feminino & 36 & 10 & 03 anos & Alimentos & $\begin{array}{l}\text { Grande } \\
\text { porte }\end{array}$ & $\begin{array}{l}\text { Analista de } \\
\text { qualidade }\end{array}$ & Operacional \\
\hline 2 & Feminino & 36 & 9 & 1 ano & Energia & $\begin{array}{l}\text { Grande } \\
\text { porte }\end{array}$ & $\begin{array}{l}\text { Gestora de } \\
\text { Projetos }\end{array}$ & Gerencial \\
\hline 3 & Feminino & 37 & 12 & 8 anos & Mercado & $\begin{array}{l}\text { Médio } \\
\text { porte }\end{array}$ & Advogada & Operacional \\
\hline 4 & Masculino & 39 & 21 & 7 anos & Hortifrut & $\begin{array}{l}\text { Médio } \\
\text { porte }\end{array}$ & Advogado & Gerencial \\
\hline 5 & Masculino & 40 & 23 & 12 anos & Energia & $\begin{array}{l}\text { Grande } \\
\text { porte }\end{array}$ & $\begin{array}{l}\text { Gestor de } \\
\text { Projetos }\end{array}$ & Gerencial \\
\hline 6 & Masculino & 31 & 10 & 7 anos & $\begin{array}{l}\text { Construção } \\
\text { Civil }\end{array}$ & $\begin{array}{l}\text { Pequeno } \\
\text { porte }\end{array}$ & $\begin{array}{c}\text { Sócio } \\
\text { Administrador }\end{array}$ & Gerencial \\
\hline 7 & Masculino & 33 & 9 & 1 ano & $\begin{array}{l}\text { Consultoria } \\
\text { jurídica }\end{array}$ & $\begin{array}{l}\text { Médio } \\
\text { porte }\end{array}$ & Advogado & Gerencial \\
\hline 8 & Feminino & 28 & 8 & 2 anos & Tecnologia & $\begin{array}{l}\text { Grande } \\
\text { Porte }\end{array}$ & $\begin{array}{c}\text { Analista de } \\
\text { Programação }\end{array}$ & Operacional \\
\hline 9 & Masculino & 36 & 20 & 6 anos & $\begin{array}{c}\text { Loja de } \\
\text { Departamento }\end{array}$ & $\begin{array}{l}\text { Grande } \\
\text { porte }\end{array}$ & Analista de TI & Operacional \\
\hline 0 & Masculino & 32 & 11 & 3 anos & Tecnlogia & $\begin{array}{l}\text { Grande } \\
\text { porte }\end{array}$ & $\begin{array}{l}\text { Desing de } \\
\text { Serviços }\end{array}$ & Operacional \\
\hline
\end{tabular}




\section{Apêndice IV - Lista de termos específicos}

\begin{tabular}{|l|l|}
\hline CTL & Consolidação das Leis do Trabalho. \\
\hline SI & Sistemas de Informação \\
\hline TI & Tecnologia da Informação \\
\hline TST & Tribunal Superior do Trabalho \\
\hline
\end{tabular}

